\author{
Marquette University \\ e-Publications@Marquette
}

\title{
$5-2018$
}

\section{The Role of Acculturation Differences and Acculturation Conflict in Latino Family Mental Health}

Kathryn E. Lawton

Marquette University

Alyson C. Gerdes

Marquette University, alyson.gerdes@marquette.edu

Theresa Lauer Kapke

Marquette University

Follow this and additional works at: https://epublications.marquette.edu/psych_fac

Part of the Psychology Commons

\section{Recommended Citation}

Lawton, Kathryn E.; Gerdes, Alyson C.; and Kapke, Theresa Lauer, "The Role of Acculturation Differences and Acculturation Conflict in Latino Family Mental Health" (2018). Psychology Faculty Research and Publications. 423.

https://epublications.marquette.edu/psych_fac/423 
Marquette University

e-Publications@Marquette

\section{Psychology Faculty Research and Publications/College of Arts and Sciences}

This paper is NOT THE PUBLISHED VERSION; but the author's final, peer-reviewed manuscript. The published version may be accessed by following the link in th citation below.

Journal of Latinx Psychology, Vol. 6, No. 2 (May 2018): 94-114. DOI. This article is (C) American Psychological Association and permission has been granted for this version to appear in ePublications@Marquette. American Psychological Association does not grant permission for this article to be further copied/distributed or hosted elsewhere without the express permission from American Psychological Association.

\section{The Role of Acculturation Differences and Acculturation Conflict in Latino Family Mental Health}

\section{Kathryn E. Lawton}

Department of Psychiatry, NorthShore University HealthSystem, Highland Park, Illinois;

\section{Alyson C. Gerdes}

Psychology Department, Marquette University

\section{Theresa Kapke}

Psychology Department, Marquette University

\section{Acknowledgement:}

The majority of Latino families in the U.S. are confronted with the challenges of acculturation, as $37 \%$ of Latinos are born outside of the U.S. (Nwosu, Batalova, \& Auclair, 2014), and 52\% of Latino children are the children of immigrants (Fry \& Passel, 2009). Because immigrants must navigate between two cultures that may differ in language, values, beliefs, and customs, acculturation may result in psychological distress (Berry, 1997), and therefore is an important context for understanding mental health in Latino families. The process of 
acculturation becomes even more complicated when examined within the context of the family, as family members may differ in their involvement with and orientation toward each culture, leading to intergenerational differences (Szapocznik, Santisteban, Kurtines, Perez-Vidal, \& Hervis, 1984). Unfortunately, research examining acculturation and mental health within the context of the family is limited, and a better understanding of the process of acculturation within the family and how acculturation differences affect family functioning and mental health among Latino families is needed.

Additionally, despite having similar or higher rates of mental health problems and risky behavior ( $\underline{C D C, 2004)}$ compared to other ethnic groups, Latino youth and their families face disparities in receiving quality mental health services (Merikangas et al., 2010). These disparities are particularly concerning given that Latinos are among the largest and fastest growing ethnic groups in the U.S. (Ennis, Rios-Vargas, \& Albert, 2011), representing $17 \%$ of the total population (U.S. Census Bureau, 2014). In order to address these disparities, more research is needed to understand the mental health of Latino families. Thus, the goal of the current study was to examine how acculturation relates to mental health in Latino families. We sought to examine if acculturation differences between Latino youth and their parents and acculturation conflict are related to family functioning and the mental health of adolescents and parents.

\section{Acculturation}

Current theory proposes that acculturation is the mutual process of change that occurs when two cultural groups come into contact (Berry, 2001). Rather than being conceptualized as a linear process in which immigrants lose aspects of their culture of origin as they gain aspects of the host culture, as with previous theories, current theory suggests that acculturation is bidirectional; specifically, identification and involvement with the new culture is independent of identification and involvement with the culture of origin (Berry, 2006). In addition to being bidirectional, the acculturation process also is conceptualized as multidimensional, with several levels of change, including behavioral and cognitive changes (Schwartz, Unger, Zamboanga, \& Szapocznik, 2010).

The adjustment or adaptation of immigrant families to new cultural demands depends on several factors (Berry, 1997). A family's reasons for moving to a new country and migration experience, as well as their reception by the host culture, likely influence their adaptation to the new culture. Because of the current sociopolitical context of the U.S., with immigration policies that have become more restrictive and punitive in recent years (Androff et al., 2011), immigrant families are likely to face significant challenges, including poverty, discrimination, and disparities in access to health care and housing, upon arrival in the U.S. (Martinez et al., 2015). Given the range of experiences that immigrant families may face due to the process of acculturation, adjustment and adaptation to acculturation, often called acculturative stress, may vary greatly among families and even between members of the same family (Berry, 1997). Acculturative stressors occur at the individual level, such as experiences of discrimination or language-related conflicts, and the family level, such as parentchild acculturation conflicts and intergenerational gaps (Vega, Zimmerman, Gil, Warheit, \& Apospori, 1993). Therefore, acculturation is an important context for understanding mental health in Latino families.

\section{Mental Health in the Latino Family Acculturation and Latino mental health}

Acculturation, specifically more acculturation or orientation to U.S. culture, is associated with increased rates of externalizing problems in Latino adolescents. For example, higher rates of delinquency are associated with more acculturation, specifically, higher generational status (Samaniego \& Gonzales, 1999) and higher Americanism (Sullivan et al., 2007). In addition, higher rates of substance and alcohol use also are associated with more acculturation, specifically, being born in the U.S., and for immigrants, increased time in the U.S. (Gil, Wagner, \& Vega, 2000). Additionally, more acculturation or orientation to U.S. culture is linked to internalizing problems, 
such as higher depressive symptomatology in girls (Lorenzo-Blanco, Unger, Ritt-Olson, Soto, \& BaezcondeGarbanati, 2011), eating disorders (Gowen, Hayward, Killen, Robinson, \& Taylor, 1999), general internalizing symptoms (ㅁawson \& Williams, 2008), and suicide attempts (Zayas, Bright, Alvarez-Sanchez, \& Cabassa, 2009).

However, this link is not consistently supported. Other studies have found that acculturation to U.S. culture is inversely related to externalizing symptoms such as substance use (Zamboanga, Schwartz, Jarvis, \& Van Tyne, 2009), and many studies have failed to find links between acculturation variables and mental health outcomes for Latino youth, including conduct disorder (Knight, Virdin, \& Roosa, 1994) and depression (Katragadda \& Tidwell, 1998). Additionally, there is evidence that biculturalism may be protective for adolescents, as it is linked to positive outcomes, including fewer internalizing problems and higher self-esteem (Smokowski \& Bacallao, 2007).

While research has examined the link between acculturation and mental health for Latino adults, few studies examine this link in the context of the family, looking specifically at Latino parents. Studies with the Latino adult population provide some information related to the acculturation-mental health link for Latino parents, but more research is needed to examine this link specifically for Latino parents. Research with Latino adults also has found a relationship between more acculturation or orientation with U.S. culture and poorer mental health outcomes, including higher substance use and dependence (Vega, Alderete, Kolody, \& Aguilar-Gaxiola, 1998), depression (Cuellar, Bastida, \& Braccio, 2004), and anxiety and bipolar disorder (Burnett-Zeigler, Bohnert, \& Ilgen, 2013). However, similar to the adolescent literature, there are inconsistencies in these findings, with several studies failing to find a link between acculturation and mental health outcomes (e.g., Shurgot, \& Knight, 2004). Additionally, a recent meta-analysis suggests that biculturalism is strongly associated with positive psychological adjustment for Latino adults (Nguyen \& Benet-Martinez, 2013).

Given the inconsistencies in findings relating to the acculturation-mental health link, several limitations in this area of research should be noted. First, the measurement of acculturation is highly variable across studies, ranging from single-item to multiple-item bidirectional scales (Cabassa, 2003). In addition, many studies use proxy measures of acculturation (Koneru, Weisman de Mamani, Flynn, \& Betancourt, 2007), including nativity status, generational status, time spent in the U.S., and language use and preference, which do not fully capture the complexity of acculturation. Proxy measures predict less variance than bidirectional measures (Ryder, Alden,

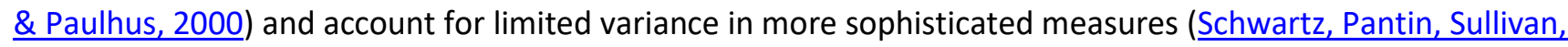
Prado, \& Szapocznik, 2006). Additionally, little attention has been paid to mechanisms of the relationship, such as mediating and moderating variables (Nguyen, 2006), as well as the context of the family. For example, understanding family functioning and family conflict regarding acculturation may help to explain why increased contact with U.S. culture may lead to negative mental health outcomes. Finally, few studies include nationally representative samples, which may contribute to the inconsistent findings.

\section{Family factors and Latino mental health}

Research has demonstrated that family factors have important implications for the mental health of Latino families and has identified family protective factors and risk factors for mental health outcomes in Latino adolescents. Supportive parenting practices, such as acceptance and attachment, are protective factors for Latino adolescents, as they are related to lower levels of depression and conduct disorder (Bámaca-Colbert \& Gayles, 2010; Gonzales, Deardorff, Formoso, Barr, \& Barrera, 2006). Additional factors that may protect against externalizing problems include parental involvement and parent-child communication (Davidson \& Cardemil, 2009) and parental monitoring (Samaniego \& Gonzales, 1999). On the other hand, family conflict is a risk factor for externalizing problems in adolescents, including anger, school misconduct (Pasch et al., 2006), aggression (Smokowski \& Bacallao, 2006), conduct problems (Gonzales et al., 2006), and substance use (McQueen, Getz, \& Bray, 2003), as well as internalizing problems, including anxiety and depression (Bámaca-Colbert \& Gayles, 
2010; Gonzales et al., 2006). Unfortunately, no research has examined how family factors influence mental health outcomes for Latino parents.

Given the impact of family functioning on mental health for Latino families, it is important to consider the role of acculturation. There is evidence that acculturation influences family functioning, suggesting that the family may be an important mechanism for understanding the link between acculturation and mental health in Latino families. For example, more acculturation or orientation to U.S. culture in adolescents is associated with increased family conflict (McQueen et al., 2003), whereas more orientation to Latino culture and biculturalism are related to less family conflict (Smokowski \& Bacallao, 2006), increased parental involvement and support (Sullivan et al., 2007), and increased family cohesion and adaptability (Smokowski, Rose, \& Bacallao, 2008). Although limited, research also suggests that parental acculturation is a key factor in family functioning; Knight and colleagues (1994) found that mothers' level of acculturation is positively related to family adaptability and family cohesion.

\section{Acculturation Differences and Conflict}

In an effort to understand the mixed findings linking acculturation and mental health outcomes for Latino families, researchers have begun to examine mechanisms that may help to explain this link and clarify previous research (see Lawton \& Gerdes, 2014 for review). Stressors related to immigration and acculturation, or acculturative stress, have emerged as important factors for understanding the acculturation-mental health link, as they are related to adolescent mental health outcomes, including anxiety, depression, and antisocial behavior (Crockett et al., 2007; Duarte et al., 2008; Romero \& Roberts, 2003; Stein, Gonzalez, \& Huq, 2012; SuarezMoreles \& Lopez, 2009) and have been shown to mediate the relationship between acculturation and mental health (Gil et al., 2000; Zamboanga et al., 2009).

Acculturative stress has been conceptualized broadly to include both individual factors (e.g., experiences of discrimination or language-related issues) and family level factors, including intergenerational gaps and family acculturation conflicts (Vega et al., 1993). Examining these family level acculturative stressors provides important context for understanding acculturation and mental health for Latino families, especially given the strong cultural value of familism within Latino culture.

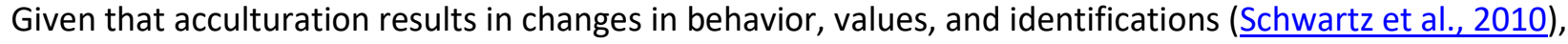
differences in these cultural aspects between adolescents and their parents may be problematic. Theoretical models suggest that within immigrant families, younger members of the family may adjust and acculturate to the host culture more quickly than older family members, leading to acculturation differences between children and parents. Acculturation conflict may occur when such differences lead to incongruent values between family members and family conflict and may exacerbate normative family struggles that often occur during adolescence (Hwang \& Wood, 2009; Szapocznik et al., 1984).

Empirical work examining acculturation differences in Latino families has focused solely on adolescent outcomes and has found mixed support for this theoretical model, often depending on analytic approach. For example, a study using difference scores found evidence that gaps in U.S. acculturation between adolescents and parents are related to increased adolescent substance use and that the relationship was mediated by family stress and parenting practices (Martinez, 2006). Lau and colleagues (2005)found evidence that acculturation "mismatches" between parent and adolescent, in which the parent is more acculturated to U.S. culture than the adolescent, leads to adolescent conduct problems. In contrast, studies by Davidson and Cardemil (2009); Marsiglia, Nagoshi, Parsai, Booth, and Castro (2014); Pasch et al. (2006); and Smokowski et al. (2008) did not find evidence of a link between acculturation gaps and mental health outcomes for Latino adolescents. 
Some studies examining family acculturation differences have focused on family members' perceptions of these differences and resulting acculturation conflict. Several studies have found links between adolescent perceptions of acculturation conflict and aggression (Smokowski \& Bacallao, 2006) as well as depression and distress (Hwang \& Wood, 2009); in both cases, the relationship was mediated by family conflict. Another study found that perceived discrepancies in values (i.e., beliefs about gender roles), but not perceptions of an acculturation gap, are related to adolescent depression (Céspedes \& Huey, 2008). In addition, acculturation conflict has been shown to predict depression above and beyond other stressors (

The mixed findings regarding acculturation gaps and family and mental health outcomes for Latino families suggest several conclusions. First, the way in which acculturation gaps are measured is important, and these findings indicate that family members' perceptions of acculturation gaps and acculturation conflicts are important in predicting family and mental health outcomes. In addition, in light of the findings of Lau and colleagues (2005), research on acculturation gaps in Latino families should examine multiple variations of the acculturation gap, such as when a parent is more acculturated to U.S. culture than the adolescent. Also, despite numerous studies examining the acculturation gap and outcomes for Latino adolescents, to our knowledge, no studies have examined mental health outcomes for parents, and more research is needed to address this gap in the literature.

\section{Current Study}

Understanding the acculturation processes of Latino adolescents and their families is crucial to addressing the mental health disparities that exist in our country. Although existing research provides a good foundation for understanding Latino family mental health, limitations in the measurement of acculturation and acculturation differences have resulted in some conflicting findings. In order for psychologists to identify methods for intervention, more research is needed to determine specific mechanisms that may account for the relationship between acculturation and mental health problems in Latino families. Family processes, including family functioning, intergenerational acculturation differences, and acculturation, may be especially important for understanding this link. The current study sought to extend previous work in several ways. First, we used comprehensive measures of acculturation completed by both adolescents and their parents, as well as measures of perceptions of acculturation conflict. Based on current multidimensional models of acculturation ( $\underline{\text { Schwartz et }}$ al., 2010), we conceptualized acculturation as behavioral (e.g., language, social preferences) and cognitive (i.e., beliefs and values). We also extended previous work by examining other measures of family functioning, including communication and satisfaction, and we sought to examine Latino family mental health contextually by including measures of parental mental health and using multiple informants to measure adolescent mental health.

The goal of the current study was to examine how acculturation (i.e., acculturation differences and acculturation conflict) relates to mental health in Latino families. The first hypothesis was that family functioning mediates the relationship between acculturation differences and internalizing problems for adolescents, externalizing problems for adolescents, and mental health outcomes for parents. Specifically, it was predicted that greater acculturation differences would be associated with decreased family functioning, which would be associated with increased mental health problems in adolescents and parents. The second hypothesis was that acculturation conflict moderates the strength of the mediated relationship between acculturation differences and internalizing problems for adolescents, externalizing problems for adolescents, and mental health outcomes for parents, via family functioning, such that the mediated relationship would be weaker for low acculturation conflict. 


\section{Method}

\section{Participants}

Participants in the current study included 84 parent-adolescent dyads recruited through three bilingual middle schools. The majority of adolescents were born in the U.S. (65\%) and were bilingual (80\%); the mean age of adolescents was 12.12 (1.04). The majority of adolescents were second generation (60\%), and there were slightly more females than males ( $53 \%$ vs. $47 \%$ ). All adolescents in the sample spoke English with $80 \%$ being fully bilingual.

The majority of parents who participated were female (83\%), were married (77\%), and had been living in the U.S. for more than 10 years (77\%). The majority of parents (81\%) were first generation immigrants/migrants, with 74\% from Mexico and 5\% from Puerto Rico; $17 \%$ of parents were born in the U.S. About $36 \%$ of parents had less than high school education, $30 \%$ had graduated from high school or received their GED, and $32 \%$ had posthigh-school education. Fifty-eight percent reported an annual household income of less than $\$ 40,000$. Language use for parents varied: $20 \%$ of parents spoke only Spanish, 38\% primarily spoke Spanish with some English, 33\% were bilingual, 2\% primarily spoke English with some Spanish, and 5\% spoke English only.

\section{Procedure}

Recruitment took place at the middle schools. The research team attended school events, during which they distributed letters describing the study and collected contact information of interested families. Families were then contacted by phone to confirm eligibility and schedule participation. Data collection occurred after school at each location. To be included in the study, the adolescents needed to be between 11 and 17 years of age, identify as Latino, and have one parent who agreed to participate and also identified as Latino.

The current study was part of a larger study on mental health in Latino families. After families arrived, written informed consent was obtained from parents and written assent was obtained from adolescents. As part of the informed consent process, parents were given the option of allowing the research team to contact one of their child's teachers. Parents and adolescents then independently completed a packet of paper and pencil questionnaires. All measures were administered in randomized order to avoid potential order effects. Participants were able to seek help or clarification from a bilingual research assistant. The questionnaires were available in English and Spanish. Participants were compensated for their participation (parents and adolescents received a $\$ 10$ and a $\$ 5$ gift card, respectively). In addition, all families received a list of referrals for community resources and mental health services.

If parents granted the research team permission to contact their adolescent's teacher, they were asked to provide the name of the teacher. When data collection was finished at each school, all of the teachers' names were provided to the schools' principals. The principals first asked the teachers if they were willing to complete a questionnaire about one or more of their students. If they agreed, the research team provided the principals with a packet of information containing a teacher letter, the student's name, and the questionnaire. Teachers received $\$ 5$ compensation for each student for whom they completed measures, to be used toward purchases for their classroom.

\section{Measures}

Adolescents and parents completed a demographic questionnaire, measures of acculturation (i.e., Acculturation Rating Scale for Mexican Americans-II, the Mexican American Cultural Values Scale for Adolescents and Adults, and acculturation conflict items) and a measure of family functioning (Family Adaptability and Cohesion Evaluation Scale-IV). Parents also completed two self-report measures (i.e., Beck Depression Inventory-II and Beck Anxiety Inventory). Adolescents, parents, and teachers completed the appropriate version of the Achenbach System of Empirically Based Assessment (i.e., Youth Self Report, Child Behavior Checklist, and 
Teacher Report Form, respectively) to assess adolescent psychopathology. All measures were available in both English and Spanish. See Table 1 for reliabilities.

Table 1

Correlations and Descriptive Statistics for Study Variables

\begin{tabular}{|c|c|c|c|c|c|c|c|c|c|c|c|c|c|c|c|c|}
\hline Variable & 1 & 2 & 3 & 4 & 5 & 6 & 7 & 8 & 9 & 10 & 11 & 12 & 13 & 14 & 15 & 16 \\
\hline 1. A LOS & 1 & & & & & & & & & & & & & & & \\
\hline 2. A AOS & .14 & 1 & & & & & & & & & & & & & & \\
\hline 3. P LOS & $.21^{+}$ & .05 & 1 & & & & & & & & & & & & & \\
\hline 4. P AOS & $-.42^{* * t}$ & .00 & -.11 & 1 & & & & & & & & & & & & \\
\hline 5. A LV & .17 & .07 & .01 & -.16 & 1 & & & & & & & & & & & \\
\hline 6. A AV & .14 & .08 & .09 & -.09 & $.20^{+}$ & 1 & & & & & & & & & & \\
\hline 7. P LV & $.25^{*}$ & -.02 & $.31^{* *}$ & -.06 & $.33^{* *}$ & .17 & 1 & & & & & & & & & \\
\hline 8. P AV & .17 & .08 & .12 & -.17 & .13 & $.26^{\circ}$ & $.57^{* * *}$ & * 1 & & & & & & & & \\
\hline 9. A ACC & -.18 & $-.20^{+}$ & $.20^{+}$ & .01 & .02 & .13 & .08 & $.27^{*}$ & 1 & & & & & & & \\
\hline 10. P ACC & -.13 & $-.19^{+}$ & .00 & -.04 & $-.18^{+}$ & .14 & -.12 & $.19^{+}$ & $.38^{\circ *}$ & 1 & & & & & & \\
\hline 11. A FF & $.25^{\circ}$ & $.25^{\circ}$ & -.06 & -.06 & $.47^{*+4}$ & $.24^{*}$ & .14 & .14 & $-.26^{\circ}$ & $-.30^{* *}$ & 1 & & & & & \\
\hline 12. P FF & $.25^{*}$ & .05 & $.18^{+}$ & -.15 & $.25^{*}$ & $-.29^{* *}$ & $.29^{*+}$ & .01 & -.13 & $-.44^{*+*}$ & $.24^{\circ}$ & 1 & & & & \\
\hline 13. YSR-I & .01 & -.12 & $.20^{+}$ & .04 & .03 & .03 & .17 & .16 & $.40^{*+*}$ & .11 & $-.26^{\circ}$ & -.07 & 1 & & & \\
\hline 14. CBCL-E & .07 & $-.20^{+}$ & .08 & -.02 & $-.27^{\circ}$ & $.19^{+}$ & .12 & $.22^{\circ}$ & $.26^{\circ}$ & $.34^{* *}$ & $-.21^{+}$ & $-.36^{* * *}$ & $.24^{\circ}$ & 1 & & \\
\hline 15. TRF-E & -.13 & -.11 & -.08 & .01 & $-.37^{* *}$ & .02 & .13 & .09 & -.01 & .07 & $-.25^{\circ}$ & -.15 & .13 & $.33^{* *}$ & * 1 & \\
\hline 16. $\mathrm{PMH}$ & -.15 & .03 & -.06 & .09 & -.03 & $.27^{*}$ & -.11 & .07 & -.09 & $.21^{+}$ & .07 & $-.29^{* *}$ & .15 & $.22^{*}$ & -.05 & 1 \\
\hline$N$ & 83 & 83 & 84 & 84 & 82 & 82 & 84 & 84 & 82 & 84 & 84 & 84 & 83 & 83 & 718 & 84 \\
\hline Mean & 3.84 & 3.87 & 4.21 & 3.01 & 4.15 & 2.80 & 3.98 & 2.83 & 1.66 & 1.733 & 38.22 & 39.21 & 53.61 & 45.63 & 47.35 & 5.86 \\
\hline$S D$ & .69 & .49 & .62 & .90 & .51 & .64 & .46 & .55 & .78 & .72 & 7.16 & 6.31 & 11.93 & 9.43 & 6.90 & 6.02 \\
\hline Reliability-E & .86 & .61 & .91 & .74 & .93 & .83 & .84 & .81 & .85 & .87 & .88 & .88 & - & - & - & .90 \\
\hline Reliability-S & - & - & .81 & .83 & - & - & .91 & .75 & - & .85 & - & .93 & - & - & - & .87 \\
\hline
\end{tabular}

Note. $\mathrm{A}=$ adolescent variable; $\mathrm{P}=$ parent variable; $\mathrm{LOS}=$ Latino orientation scale; $\mathrm{AOS}=\mathrm{U} . \mathrm{S}$. orientation scale; $\mathrm{LV}=$ Latino values scale; $\mathrm{AV}=\mathrm{U} . \mathrm{S}$. values scale; $\mathrm{FF}=$ family functioning (composite of communication and satisfaction given high correlation of the two variables); $\mathrm{ACC}=$ acculturation conflict; YSR-I = adolescent-reported internalizing symptoms; CBCL-E = parent-reported adolescent externalizing symptoms; TRF-E = teacher-reported adolescent externalizing symptoms; PMH = parental mental health (composite of BDI-II and BAI given high correlation of the two variables); Reliability-E = reliability for English version of measure; Reliability-S = reliability for Spanish version of measure.

${ }^{+} p<.10 .{ }^{*} p \leq .05 .{ }^{* *} p \leq .01 .{ }^{* * *} p \leq .001$.

Table 1. Correlations and Descriptive Statistics for Study Variables

\begin{tabular}{|c|c|c|c|c|c|c|c|c|c|c|c|c|c|c|c|c|}
\hline Variable & 1 & 2 & 3 & 4 & 5 & 6 & 7 & 8 & 9 & 10 & 11 & 12 & 13 & 14 & 15 & 16 \\
\hline 1. A LOS & 1 & & & & & & & & & & & & & & & \\
\hline 2. AAOS & .14 & 1 & & & & & & & & & & & & & & \\
\hline 3. P LOS & $.21^{-}$ & .05 & 1 & & & & & & & & & & & & & \\
\hline 4. PAOS & $\begin{array}{l}- \\
.42 * * \\
*\end{array}$ & .00 & -.11 & 1 & & & & & & & & & & & & \\
\hline 5. A LV & .17 & .07 & .01 & $\begin{array}{l}- \\
.16 \\
\end{array}$ & 1 & & & & & & & & & & & \\
\hline 6. A AV & .14 & .08 & .09 & $\begin{array}{l}- \\
.09\end{array}$ & $.20^{+}$ & 1 & & & & & & & & & & \\
\hline 7. P LV & $.25^{*}$ & $\begin{array}{l}- \\
.02 \\
\end{array}$ & $\begin{array}{l}.31 * \\
*\end{array}$ & $\begin{array}{l}- \\
.06\end{array}$ & $.33^{* *}$ & .17 & 1 & & & & & & & & & \\
\hline 8. P AV & .17 & .08 & .12 & $\begin{array}{l}- \\
.17\end{array}$ & .13 & $.26^{*}$ & $\begin{array}{l}.57^{* *} \\
*\end{array}$ & 1 & & & & & & & & \\
\hline 9. A ACC & -.18 & $\begin{array}{l}- \\
.20 \\
+\end{array}$ & $.20^{+}$ & .01 & .02 & .13 & .08 & $\begin{array}{l}.27 \\
*\end{array}$ & 1 & & & & & & & \\
\hline $\begin{array}{l}\text { 10. P } \\
\text { ACC }\end{array}$ & -.13 & $\begin{array}{l}- \\
.19 \\
+\end{array}$ & .00 & $\begin{array}{l}- \\
.04\end{array}$ & $\begin{array}{l}.18- \\
\end{array}$ & .14 & -.12 & $\begin{array}{l}.19 \\
+\end{array}$ & $.38 * *$ & 1 & & & & & & \\
\hline 11. A FF & $.25^{*}$ & $\begin{array}{l}.25 \\
* \\
\end{array}$ & -.06 & $\begin{array}{l}- \\
.06 \\
\end{array}$ & $\begin{array}{l}.47^{* *} \\
* \\
\end{array}$ & $.24^{*}$ & .14 & .14 & $-.26 *$ & $\begin{array}{l}- \\
.30 * *\end{array}$ & 1 & & & & & \\
\hline
\end{tabular}




\begin{tabular}{|c|c|c|c|c|c|c|c|c|c|c|c|c|c|c|c|c|}
\hline 12. P FF & $.25^{*}$ & .05 & $.18+$ & $\begin{array}{l}- \\
.15\end{array}$ & $.25 *$ & $\begin{array}{l}- \\
.29 * \\
*\end{array}$ & $.29 * *$ & .01 & -.13 & $\begin{array}{l}- \\
.44^{* *} \\
*\end{array}$ & $.24 *$ & 1 & & & & \\
\hline 13. YSR-I & .01 & $\begin{array}{l}- \\
.12\end{array}$ & $.20+$ & .04 & .03 & .03 & .17 & .16 & $\begin{array}{l}.40 * * \\
*\end{array}$ & .11 & $\begin{array}{l}- \\
.26 *\end{array}$ & -.07 & 1 & & & \\
\hline $\begin{array}{l}14 . \\
C B C L-E\end{array}$ & .07 & $\begin{array}{l}- \\
.20 \\
+\end{array}$ & .08 & $\begin{array}{l}- \\
-02\end{array}$ & $-.27 *$ & $.19+$ & .12 & $\begin{array}{l}.22 \\
*\end{array}$ & $.26 *$ & $.34 * *$ & $\begin{array}{l}- \\
.21 *\end{array}$ & $\begin{array}{l}- \\
.36 * * \\
*\end{array}$ & $.24 *$ & 1 & & \\
\hline $\begin{array}{l}\text { 15. TRF- } \\
\text { E }\end{array}$ & -.13 & $\begin{array}{l}- \\
.11\end{array}$ & -.08 & .01 & $\begin{array}{l}- \\
.37^{* *}\end{array}$ & .02 & .13 & .09 & -.01 & .07 & $\begin{array}{l}- \\
25 *\end{array}$ & -.15 & .13 & $\begin{array}{l}.33^{*} \\
*\end{array}$ & 1 & \\
\hline 16. PMH & -.15 & .03 & -.06 & .09 & -.03 & $.27 *$ & -.11 & .07 & -.09 & $.21+$ & .07 & $\begin{array}{l}- \\
.29 * *\end{array}$ & .15 & $.22 *$ & -.05 & 1 \\
\hline$N$ & 83 & 83 & 84 & 84 & 82 & 82 & 84 & 84 & 82 & 84 & 84 & 84 & 83 & 83 & 71 & 84 \\
\hline Mean & 3.84 & $\begin{array}{l}3.8 \\
7 \\
\end{array}$ & 4.21 & $\begin{array}{l}3.0 \\
1 \\
\end{array}$ & 4.15 & 2.80 & 3.98 & $\begin{array}{l}2.8 \\
3 \\
\end{array}$ & 1.66 & 1.73 & $\begin{array}{l}38.2 \\
2 \\
\end{array}$ & 39.21 & $\begin{array}{l}53.6 \\
1 \\
\end{array}$ & $\begin{array}{l}45.6 \\
3\end{array}$ & $\begin{array}{l}47.3 \\
5 \\
\end{array}$ & $\begin{array}{l}5.8 \\
6 \\
\end{array}$ \\
\hline$S D$ & .69 & .49 & .62 & .90 & .51 & .64 & .46 & .55 & .78 & .72 & 7.16 & 6.31 & $\begin{array}{l}11.9 \\
3 \\
\end{array}$ & 9.43 & 6.90 & $\begin{array}{l}6.0 \\
2 \\
\end{array}$ \\
\hline $\begin{array}{l}\text { Reliabilit } \\
y-E\end{array}$ & .86 & .61 & .91 & .74 & .93 & .83 & .84 & .81 & .85 & .87 & .88 & .88 & - & - & - & .90 \\
\hline $\begin{array}{l}\text { Reliabilit } \\
\text { y-S }\end{array}$ & - & - & .81 & .83 & - & - & .91 & .75 & - & .85 & - & .93 & - & - & - & .87 \\
\hline
\end{tabular}

Note. $\mathrm{A}=$ adolescent variable; $\mathrm{P}=$ parent variable; $\mathrm{LOS}=$ Latino orientation scale; $\mathrm{AOS}=\mathrm{U} . \mathrm{S}$. orientation scale; $\mathrm{LV}$ $=$ Latino values scale; $A V=U . S$. values scale; $F F=$ family functioning (composite of communication and satisfaction given high correlation of the two variables); $A C C=$ acculturation conflict; YSR-I = adolescentreported internalizing symptoms; $\mathrm{CBCL}-\mathrm{E}=$ parent-reported adolescent externalizing symptoms; TRF-E = teacher-reported adolescent externalizing symptoms; $\mathrm{PMH}=$ parental mental health (composite of BDI-II and $\mathrm{BAI}$ given high correlation of the two variables); Reliability- $\mathrm{E}=$ reliability for English version of measure; Reliability-S = reliability for Spanish version of measure.

$+p<.10{ }^{*} p \leq .05 . * * p \leq .01 .^{* * *} p \leq .001$.

Acculturation Rating Scale for Mexican Americans-II (ARSMA-II; Cuellar, Arnold, \& Maldonado, 1995) The ARSMA-II is a widely used 30-item, bidirectional measure of acculturation that measures an individual's Mexican orientation (Mexican Orientation Subscale [MOS]) and Anglo orientation (Anglo Orientation Subscale [AOS]) on a 5-point Likert scale. This measure was used to assess behavioral acculturation, as items focus on behavior and behavioral preferences (e.g., "My thinking is done in the Spanish language," "I enjoy reading books in English"). The current study modified the ARSMA-II by substituting "Latino" for "Mexican" or "Mexican American" in an effort to make it more suitable to use with a wider Latino population (Latino Orientation Subscale [LOS]). This method has been used previously and maintains the psychometric properties of the measure (Lawton, Gerdes, Haack, \& Schneider, 2014). The measure has demonstrated good reliability and validity (Cuellar et al., 1995). High subscales scores on LOS and AOS indicate more behavioral orientation to Latino culture and Anglo culture, respectively.

Mexican American Cultural Values Scale for Adolescents and Adults (MACVS; Knight et al., 2010) The MACVS is a 50 -item measure that assesses cultural constructs relevant to Latino and mainstream American culture on a 5-point Likert scale. This measure was used to assess cognitive acculturation. The Mexican American (Latino) values scale (LV) combines subscales of familism (e.g., "parents should teach their children that the family always comes first"), respect (e.g., "children should respect adult relatives as if they were parents"), religion (e.g., "God is first, family is second"), and traditional gender roles (e.g., "families need to watch over and protect teenage girls more than teenage boys"). The mainstream values scale (AV) combines subscales of material success (e.g., "owning a lot of nice things makes one very happy"), independence and self-reliance (e.g., "as children get older their parents should allow them to make their own decisions"), and competition and personal achievement (e.g., "parents should teach their children to compete to win"). High subscale scores on 
the Latino values scale and mainstream values scale indicate strong endorsement and more orientation to Latino culture and mainstream U.S. culture, respectively. The MACVS has shown good reliability and construct validity (Knight et al., 2010). Items do not specify a particular Latino group (i.e., Mexican), and therefore the measure is likely acceptable to use with a wide Latino population.

\section{Acculturation conflict}

Acculturation conflict was measured using the mean of a 4-item scale that has been used in previous research (e.g., Smokowski, Rose, \& Bacallao, 2010; Vega, Khoury, Zimmerman, Gil, \& Warheit, 1995). Responses were measured on a 5-point Likert scale from not at all to frequently (e.g., "how often have you had problems with your family because you prefer American customs," "how often do you get upset at your parents because they don't know American ways" [not included in parent version]). Internal consistency has been shown to be .76 for adolescents and .87 for parents (Smokowski et al., 2010). The current study used the mean of these items.

Family Adaptability and Cohesion Evaluation Scale-IV (FACES-IV; Olson, 2011)

FACES-IV is a 62-item self-report measure developed to assess family functioning. The current study examined two subscales, the Family Satisfaction Scale and the Family Communication Scale. The Family Satisfaction Scale is a 10-item scale measured on a Likert scale from 1 (very dissatisfied) to 5 (extremely satisfied). This subscale assesses satisfaction with family cohesion and adaptability (e.g., satisfaction with "your family's ability to cope with stress," "family members' concern for each other"), with high scores indicating more satisfaction. The Family Communication Scale is a 10-item scale measured on a Likert scale from 1 (strongly disagree) to 5 (strongly agree) that assesses communication within the family (e.g., "family members are very good listeners," "family members try to understand each other's feelings"). Both the English and Spanish versions have demonstrated good psychometric properties (Groenenberg, Sharma, Green, \& Fleming, 2013; Rivero, MartinezPampliega, \& Olson, 2010).

Beck Depression Inventory-II (Beck, Steer, \& Brown, 1996) The BDI-II is a 21-item self-report measure that assesses symptoms of depression. Each item has four choices, and respondents are asked to choose which statement best describes the way they have been feeling for the past two weeks. The BDI-II has demonstrated strong psychometric characteristics in English (Beck et al., 1996) and in Spanish (Wiebe \& Penley, 2005).

Beck Anxiety Inventory (BAl; Beck \& Steer, 1993)

The BAI is a 21-item measure assessing symptoms of anxiety. Each item asks respondents to rate how much they have been bothered by that symptom (e.g., "nervous," "unsteady"), rated on a 4-point scale ranging from 0 (not at all) to 3 (severely). The BAI has good psychometric properties in English (Beck, Epstein, Brown, \& Steer, 1988) and Spanish (Magán, Sanz, \& García-Vera, 2008).

Achenbach System of Empirically Based Assessment (ASEBA; Achenbach \& Rescorla, 2001) The ASEBA was used to measure adolescent psychopathology across raters. These measures are widely used to assess a range of emotional and behavioral problems in children and adolescents using a 3-point scale via selfreport (Youth Self Report/11-18), parent report (Child Behavior Checklist/6-18, Spanish translation by RubioStipec, Bird, Canino, \& Gould, 1990), and teacher-report (Teacher Report Form/6-18). The measures demonstrate strong psychometric properties (Achenbach \& Rescorla, 2001). The current study examined the Total Internalizing and Total Externalizing subscales, with higher scores indicating more psychopathology.

\section{Analyses}

\section{Mediation}

Mediation analyses were conducted using several methods (see Figure 1for conceptual model). First, we used the causal steps method as outlined by Baron and Kenny (1986) to examine the total, direct, and indirect effects 
of acculturation differences on mental health outcomes via family functioning based on regression analyses. According to this method, several conditions must be met to establish mediation: the independent variable predicts significant variance in the outcome variable, the independent variable predicts significant variance in the mediator, the mediator predicts significant variance in the outcome variable, and when the mediator is controlled for, the link between the independent variable and the outcome is reduced. If all conditions are met, mediation has occurred (Baron \& Kenny, 1986). We also examined the significance of the indirect effects using Sobel's test (Sobel, 1982).

(A) Total Effects

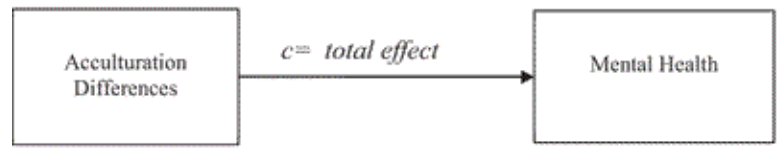

(C) Moderated Mediation²

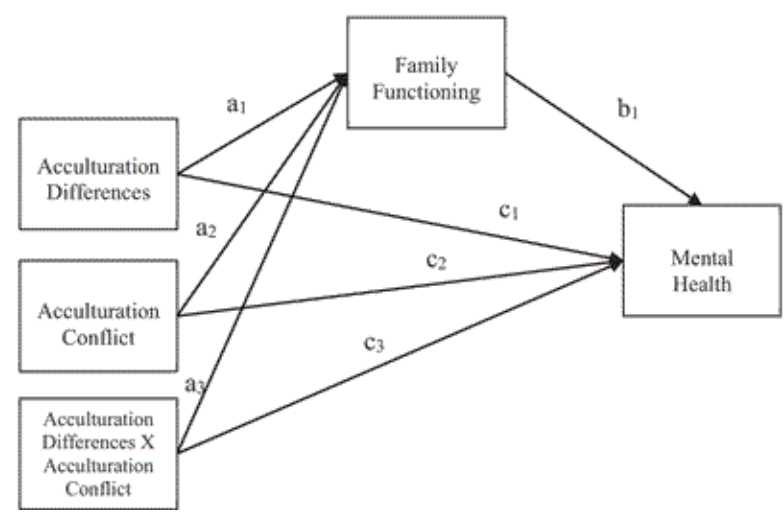

(B) Mediation'

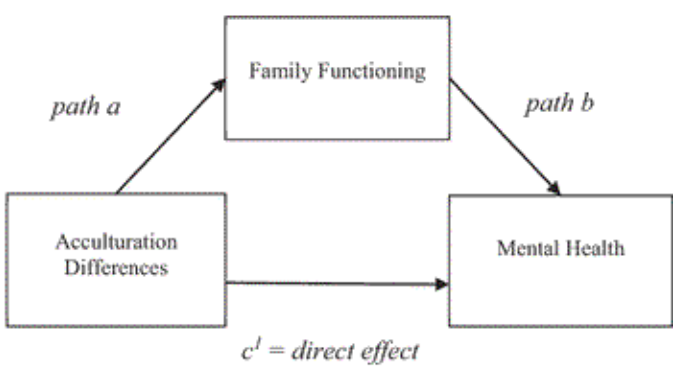

Figure 1. Conceptual models.

Finally, based on critiques that the causal steps method has low power (MacKinnon, Lockwood, Hoffman, West, \& Sheets, 2002) and that testing the significance of the indirect effect is potentially limited by its assumption that the distribution is normal (Preacher \& Hayes, 2004), we also examined the significance of the indirect effect using bootstrapping procedures (Hayes, 2009; Preacher \& Hayes, 2004). Researchers have recommended using bootstrapping procedures to determine the $95 \%$ confidence interval in which the indirect effect falls as a means of determining the significance. Bootstrapping is a nonparametric test that draws a large number of samples, with replacement, from the dataset and calculates the indirect effect, which is tested against the null hypothesis that the indirect effect is zero. The confidence interval produced by the bootstrapping procedure is examined and if zero is not included within the confidence interval, the indirect effect is considered significant, and it is concluded that mediation is present (Preacher \& Hayes, 2004).

Moderated mediation

Moderated mediation analyses were conducted following guidelines outlined in Preacher, Rucker, and Hayes (2007; see Figure 1). Specifically, indirect effects of the hypothesized mediated pathways were compared at high and low levels of the moderator (i.e., acculturation conflict), operationalized as \pm 1 standard deviation from the mean. In addition, bias-corrected bootstrapping procedures with 5000 resamples were utilized to calculate $95 \%$ confidence intervals of the indirect effect at each level of the moderator. Similar to bootstrapping for mediation analyses, the confidence interval produced by the bootstrapping procedure is examined and if zero is not included within the confidence interval, the conditional indirect effect is considered significant, and it is concluded that moderated mediation is present (Preacher et al., 2007). 


\section{Results}

\section{Correlations and Descriptive Results}

Correlations, means, and standard deviations of all variables, as well as each measure's reliability, are presented in Table 1.

\section{Adolescent variables}

Adolescents had moderately strong behavioral orientation to both Latino and U.S. culture $(M=3.84, S D=$ .69; $M=3.87, S D=.49$, respectively). In terms of cognitive orientation, adolescents were strongly oriented to Latino culture $(M=4.15, S D=.51)$ and moderately oriented to U.S. culture $(M=2.80, S D=.64)$. Adolescent reports of family functioning, in terms of communication $(M=38.55, S D=6.86)$ and satisfaction $(M=37.89, S D=$ 8.65), indicate high levels of positive communication and moderate levels of satisfaction (Olson, 2011). Given the high correlation between adolescent communication and adolescent satisfaction, these subscales were combined into an adolescent family functioning subscale using the mean of the two subscales $(M=38.22, S D=$ 7.16).

Across all three reporters, $4 \%-17 \%$ of adolescents had clinically elevated levels of internalizing problems, and $1 \%-5 \%$ had clinically elevated levels of externalizing problems, which is similar to prevalence rates found in national samples (Merikangas et al., 2011). Reports of adolescent internalizing and externalizing problems were not highly correlated across reporters and therefore not combined. Instead, given that previous research has suggested that adolescents are more valid reporters of their own internalizing problems, whereas parents and teachers are more valid reporters of externalizing problems (see Smith, 2007), adolescent-reports of internalizing problems and parent- and teacher-reports of externalizing problems were used in the analyses.

\section{Parental variables}

Parents were strongly oriented to Latino culture, in terms of behavior $(M=4.21, S D=.62)$ and cognition $(M=$ $3.98, S D=.46)$, and had moderate orientation to U.S. culture, in terms of behavior $(M=3.01, S D=.90)$ and cognition $(M=2.83, S D=.55)$. Parental reports of family functioning, in terms of communication $(M=$ $40.02, S D=6.42)$ and satisfaction $(M=38.40, S D=7.00)$, indicate high levels of positive communication and moderate levels of satisfaction (Olson, 2011). Given the high correlation between parental communication and parental satisfaction, these subscales were combined into a parental family functioning subscale using the mean of the two subscales $(M=39.21, S D=6.31)$. Eight percent of parents reported moderate to severe levels of symptoms of anxiety and depression. Given the high correlation between anxiety and depression, these measures also were combined into a parental mental health scale using the mean of the two measures $(M=$ $5.86, S D=6.02)$.

\section{Acculturation and mental health}

Correlational analyses indicated that there were no significant relationships between any adolescent acculturation variable and adolescent internalizing problems (see Table 1). There was a significant inverse relationship between adolescent $L V$ and parent-reported and teacher-reported externalizing problems, $r=$ $-.27, p \leq .05 ; r=-.37, p \leq .01$, indicating that adolescents with low Latino cognitive acculturation had more externalizing problems. In addition, there were no significant relationships between any parental acculturation variables and parental mental health.

\section{Acculturation differences}

Intergenerational acculturation differences were calculated by taking the absolute value of the difference between parent acculturation and adolescent acculturation for each acculturation domain. Means, standard deviations, and correlations for these difference scores are presented in $\underline{T}$ able 2 . The absolute value was used because the total difference, rather than direction of the difference, was of interest in the current study. This 
method has been used in previous studies (Davidson \& Cardemil, 2009). Correlational analyses indicated that there were no significant relationships between parent-adolescent acculturation differences and adolescent mental health outcomes. Differences in LV were significantly related to parental mental health outcomes, $r=$ $.23, p \leq .05$, indicating that greater parent-adolescent differences in Latino cognitive acculturation was related to parental mental health symptoms.

Table 2

Descriptive Statistics and Correlations for Parent-Adolescent Acculturation Differences

\begin{tabular}{lcccccccrrr}
\hline & AFF & PFF & A ACC & P ACC & YSR-I & CBCL-E & TRF-E & PMH & Mean & $S D$ \\
\hline LOS & $-.19^{+}$ & $-.25^{*}$ & $.32^{* *}$ & $.19^{+}$ & .13 & -.10 & .14 & .16 & .68 & .58 \\
LV & -.09 & $-.20^{+}$ & -.13 & .08 & $-.18^{+}$ & .00 & -.03 & $.23^{*}$ & .46 & .36 \\
AOS & .10 & $.21^{+}$ & .04 & -.05 & -.05 & -.10 & -.12 & $-.18^{+}$ & 1.08 & .79 \\
AV & .01 & .09 & .08 & .03 & -.08 & -.10 & -.13 & $.21^{+}$ & .56 & .47 \\
\hline
\end{tabular}

Note, $\quad N=83$. LOS $=$ Latino behavioral acculturation differences; $\mathrm{LV}=$ Latino cognitive acculturation differences; AOS $=$ U.S. mainstream behavioral acculturation differences; $\mathrm{AV}=\mathrm{U} . \mathrm{S}$. mainstream cognitive acculturation differences; AFF $=$ adolescent-reported family functioning; PFF $=$ parent-reported family functioning; $\mathrm{A}$ ACC $=$ adolescent acculturation conflict; $\mathrm{P}$ ACC $=$ parental acculturation conflict; YSR-I = adolescent-reported internalizing symptoms; CBCL-E = parent-reported adolescent externalizing symptoms; TRF-E = teacher-reported adolescent externalizing symptoms, PMH = parental mental health.

${ }^{+} p<.10 . \quad * p \leq .01 .{ }^{*} p \leq .05$.

Table 2: Descriptive Statistics and Correlations for Parent-Adolescent Acculturation Differences

\begin{tabular}{|l|c|c|c|c|c|c|c|c|c|c|}
\hline & AFF & PFF & A ACC & P ACC & YSR-I & CBCL-E & TRF-E & PMH & Mean & SD \\
\hline LOS & $-.19^{+}$ & $-.25^{*}$ & $.32^{* *}$ & $.19^{+}$ & .13 & -.10 & .14 & .16 & .68 & .58 \\
\hline LV & -.09 & $-.20^{+}$ & -.13 & .08 & $-.18^{+}$ & .00 & -.03 & $.23^{*}$ & .46 & .36 \\
\hline AOS & .10 & $.21^{+}$ & .04 & -.05 & -.05 & -.10 & -.12 & $-.18^{+}$ & 1.08 & .79 \\
\hline AV & .01 & .09 & .08 & .03 & -.08 & -.10 & -.13 & $.21^{+}$ & .56 & .47 \\
\hline
\end{tabular}

Note. $N=83$. LOS = Latino behavioral acculturation differences; LV = Latino cognitive acculturation differences; $A O S=U . S$. mainstream behavioral acculturation differences; $A V=$ U.S. mainstream cognitive acculturation differences; $A F F=$ adolescent-reported family functioning; PFF = parent-reported family functioning; $A$ ACC = adolescent accul- turation conflict; $P$ ACC = parental acculturation conflict; YSR-I = adolescent-reported internalizing symptoms; $C B C L-E=$ parent-reported adolescent externalizing symptoms; TRF-E = teacher-reported adolescent externalizing symptoms, $\mathrm{PMH}=$ parental mental health. ${ }^{+} p<.10{ }^{*} p<.01 .^{* *} p<.05$.

\section{Acculturation conflict}

Correlational analyses indicated that adolescent report of acculturation conflict was positively related to parental $\mathrm{AV}, r=.27, p \leq .05$, negatively related to adolescent report of family functioning, $r=-.26, p \leq .05$, positively related to adolescent internalizing symptoms, $r=.40, p \leq .001$, and parent-report of externalizing symptoms, $r=.26, p \leq .05$. In addition, parent report of acculturation conflict was negatively related to adolescent and parent reports of family functioning, $r=-.30, p \leq .01 ; r=-.44, p \leq .001$, respectively and positively related to parent-reported adolescent externalizing problems, $r=.34, p \leq .01$.

\section{Mediation Analyses}

Hypothesis 1 was that family functioning would mediate the relationship between acculturation differences and internalizing problems for adolescents, externalizing problems for adolescents, and mental health outcomes for parents. Specifically, it was predicted that greater acculturation differences would be associated with decreased family functioning, which would be associated with increased mental health problems in adolescents and parents. To test Hypothesis 1, mediation was examined using several methods: causal steps method as outlined 
by Baron and Kenny (1986), significance testing of the indirect effects using Sobel's test (Sobel, 1982), and significance testing of the indirect effect using bootstrapping procedures (Hayes, 2009; Preacher \& Hayes, 2004).

\section{Adolescent Internalizing Outcomes}

\section{Causal steps method}

Results for mediation analyses for adolescent outcomes are presented in Table 3. No pathways for adolescent internalizing problems met the criteria for mediation. Of note, family functioning predicted significant variance in adolescent internalizing problems in the expected direction $(6=-.26, p \leq .05)$.

Table 3

Results of Mediation Analyses for Adolescent Outcomes: Causal Steps, Indirect Effects, and 95\% Confidence Interval for Bootstrapping Estimates

\begin{tabular}{|c|c|c|c|c|c|c|c|c|c|c|c|c|c|}
\hline \multirow[b]{2}{*}{ IV } & \multirow[b]{2}{*}{ Mediator } & \multirow[b]{2}{*}{ DV } & \multicolumn{2}{|c|}{$\begin{array}{l}\text { Total effect of } \\
\text { IV on DV }\end{array}$} & \multicolumn{2}{|c|}{$\begin{array}{l}\text { Effects of IV } \\
\text { on mediator) }\end{array}$} & \multicolumn{2}{|c|}{$\begin{array}{c}\text { Effect of M } \\
\text { on DV }\end{array}$} & \multicolumn{2}{|c|}{ Direct effects } & \multirow{2}{*}{$\begin{array}{c}\text { Indirect } \\
\text { effect }\end{array}$} & \multicolumn{2}{|c|}{$95 \% \mathrm{CI}$} \\
\hline & & & B & Beta & B & Beta & B & Beta & B & Beta & & Lower & Upl \\
\hline \multicolumn{14}{|c|}{ Internalizing } \\
\hline LOS & Fam Fx & YSR-I & 2.66 & .13 & $-2.31^{+}$ & $-.19^{+}$ & $-.43^{\circ}$ & $-.26^{\circ}$ & 1.72 & .08 & $.67^{+}$ & -.00 & 2.85 \\
\hline LV & $\mathrm{mFx}$ & YSR-I & $-6.05^{+}$ & $-.18^{+}$ & -1.75 & -.09 & $-.43^{\circ}$ & $-.26^{*}$ & $-6.86^{+}$ & $-.21^{+}$ & .81 & -1.27 & 4.00 \\
\hline AOS & Fam Fx & YSR-I & -.70 & -.05 & .88 & .10 & $-.43^{\circ}$ & $-.26^{\circ}$ & -.33 & -.02 & -.41 & -1.58 & .34 \\
\hline AV & $\mathrm{m} F \mathrm{x}$ & YSR-I & -1.97 & -.08 & & .01 & $-.43^{\circ}$ & & -1.93 & 8 & & -2.06 & 1.47 \\
\hline \multicolumn{14}{|c|}{ Externaliziı } \\
\hline \multirow[t]{2}{*}{ LOS } & Fam Fx & CBCL-E & -1.55 & -.10 & $-2.31^{+}$ & $-.19^{+}$ & $-.27^{+}$ & $-.21^{+}$ & -2.25 & -.14 & .70 & -.04 & 2.48 \\
\hline & Fam Fx & TRF-E & 1.56 & .14 & $-2.31^{+}$ & $-.19^{+}$ & $-.24^{*}$ & $-.25^{*}$ & 1.12 & .10 & .4 & -.04 & 1.71 \\
\hline \multirow[t]{2}{*}{ LV } & Fam Fx & CBCL-E & .08 & .00 & -1.75 & -.09 & $-.27^{+}$ & $-.21^{+}$ & -.42 & -.02 & .49 & -.57 & 3.43 \\
\hline & Fam Fx & TRF-E & -.54 & -.03 & -1.75 & -.09 & $-.24^{*}$ & $-.25^{*}$ & -1.08 & -.06 & .54 & -.60 & 3.04 \\
\hline \multirow[t]{2}{*}{ AOS } & Fam Fx & CBCL-E & -1.19 & -.10 & .88 & .10 & $-.27^{+}$ & $-.21^{+}$ & -.96 & -.08 & -.23 & -1.36 & .18 \\
\hline & Fam Fx & TRF-E & -1.03 & -.12 & .88 & .10 & $-.24^{*}$ & $-.25^{*}$ & -.83 & -.10 & -.21 & -1.10 & .17 \\
\hline \multirow[t]{2}{*}{ AV } & Fam Fx & CBCL-E & -2.12 & -.10 & .09 & .01 & $-.27^{+}$ & $-.21^{+}$ & -2.10 & -.10 & -.02 & -1.24 & 1.35 \\
\hline & Fam Fx & TRF-E & -1.82 & -.13 & .09 & .01 & $-.24^{*}$ & $-.25^{\circ}$ & -1.84 & -.13 & .02 & -1.16 & 1.31 \\
\hline
\end{tabular}

Note. $\quad N=83 . \mathrm{LOS}=$ Latino behavioral acculturation differences; $\mathrm{LV}=$ Latino cognitive acculturation differences; AOS $=$ U.S. mainstream behavioral acculturation differences; $\mathrm{AV}=$ U.S. mainstream cognitive acculturation differences; Fam Fx = adolescent-reported family functioning; YSR-I = adolescent-reported internalizing symptoms; CBCL-E = parent-reported adolescent externalizing symptoms; TRF-E = teacher-reported adolescent externalizing symptoms.

${ }^{+} p<.10 .{ }^{*} p \leq .01$.

Table 3: Results of Mediation Analyses for Adolescent Outcomes: Causal Steps, Indirect Effects, and 95\% Confidence Interval for Bootstrapping Estimates

\begin{tabular}{|c|c|c|c|c|c|c|c|c|c|c|c|c|c|}
\hline & & & $\begin{array}{l}\text { Total } \\
\text { effect of } \\
\text { IV on DV }\end{array}$ & & $\begin{array}{l}\text { Effects of } \\
\text { IV } \\
\text { on } \\
\text { mediator) }\end{array}$ & & $\begin{array}{l}\text { Effect } \\
\text { of M } \\
\text { on DV }\end{array}$ & & $\begin{array}{l}\text { Direct } \\
\text { effects }\end{array}$ & & & $\begin{array}{l}95 \% \\
\mathrm{Cl} \\
\end{array}$ & \\
\hline IV & Mediator & DV & B & Beta & B & Beta & B & Beta & B & Beta & $\begin{array}{l}\text { Indirect } \\
\text { effect }\end{array}$ & Lower & Upper \\
\hline \multicolumn{14}{|c|}{ Internalizing } \\
\hline LOS & Fam Fx & YSR-I & 2.66 & .13 & $-2.31+$ & .19+ & $-.43^{*}$ & $.26^{*}$ & 1.72 & .08 & $.67+$ & -.00 & 2.85 \\
\hline LV & Fam Fx & YSR-I & $-6.05+$ & $\begin{array}{r}.18+ \\
- \\
\end{array}$ & -1.75 & -.09 & $-.43 *$ & $.26^{-}$ & $-6.86{ }_{-}^{*}$ &. & .81 & -1.27 & 4.00 \\
\hline AOS & Fam Fx & YSR-I & -.70 & -.05 & .88 & .10 & $-.43_{*}^{*}$ & $\begin{array}{r}- \\
.26^{*} \\
\end{array}$ & -.33 & -.02 & -.41 & -1.58 & .34 \\
\hline AV & Fam Fx & YSR-I & -1.97 & -.08 & .09 & .01 & $-.43 *$ & $.26^{-}$ & -1.93 & -.08 & -.33 & -2.06 & 1.47 \\
\hline \multicolumn{14}{|c|}{ Externalizing } \\
\hline LOS & Fam Fx & $\begin{array}{l}\text { CBCL- } \\
\text { E }\end{array}$ & -1.55 & -.10 & $-2.31 *$ & $.19 *$ & $-.27-$ & $\begin{array}{r}- \\
.21+\end{array}$ & -2.25 & -.14 & .70 & -.04 & 2.48 \\
\hline & Fam Fx & TRF-E & 1.56 & .14 & $-2.31+$ & $.19+$ & $-.24 *$ & $25^{*}$ & 1.12 & .10 & .44 & -.04 & 1.71 \\
\hline
\end{tabular}




\begin{tabular}{|c|c|c|c|c|c|c|c|c|c|c|c|c|c|}
\hline LV & Fam Fx & $\begin{array}{l}\text { CBCL- } \\
\mathrm{E}\end{array}$ & .08 & .00 & -1.75 & -.09 & $-.27+$ & $\begin{array}{r}- \\
.21+ \\
\end{array}$ & -.42 & -.02 & 9 & -.57 & 3.43 \\
\hline & Fam Fx & TRF-E & -.54 & -.03 & -1.75 & -.09 & $-.24 *$ & $.25^{-}$ & -1.08 & -.06 & .54 & -.60 & 3.04 \\
\hline AOS & Fam Fx & $\begin{array}{l}\text { CBCL- } \\
\mathrm{E}\end{array}$ & -1.19 & -.10 & .88 & .10 & $-.27+$ & $.21+$ & -.96 & -.08 & -.23 & -1.36 & .18 \\
\hline & Fam Fx & TRF-E & -1.03 & -.12 & .88 & .10 & $-.24 *$ & $.25 *$ & -.83 & -.10 & -.21 & -1.10 & .17 \\
\hline AV & Fam Fx & $\begin{array}{l}\text { CBCL- } \\
\mathrm{E}\end{array}$ & -2.12 & -.10 & .09 & .01 & $-.27+$ & $\begin{array}{r}- \\
.21+\end{array}$ & -2.10 & -.10 & -.02 & -1.24 & 1.35 \\
\hline & Fam Fx & TRF-E & -1.82 & -.13 & .09 & .01 & $-.24^{*}$ & $.25^{-}$ & -1.84 & -.13 & .02 & -1.16 & 1.31 \\
\hline
\end{tabular}

Note. $N=83$. LOS = Latino behavioral acculturation differences; LV = Latino cognitive acculturation differences; AOS = U.S. mainstream behavioral acculturation differences; $A V=$ U.S. mainstream cognitive acculturation differences; Fam Fx = adolescent-reported family functioning; YSR-I = adolescent-reported internalizing symptoms; CBCL-E = parent-reported adolescent externalizing symptoms; TRF-E = teacher-reported adolescent externalizing symptoms.

$+p<.10 .^{*} p<.01$.

\section{Sobel's test}

Mediation also was examined through significance testing of the indirect effect, using Sobel's test (Sobel, 1982). There were no significant indirect effects of acculturation differences on adolescent internalizing problems via family functioning.

\section{Bootstrapping procedures}

Bias-corrected bootstrapping procedures indicated no significant indirect effects of acculturation differences on adolescent internalizing problems via family functioning.

\section{Adolescent Externalizing Outcomes}

\section{Causal steps method}

No pathways for adolescent externalizing problems met the criteria for mediation. No acculturation differences had significant direct effects on parent- or teacher-reported adolescent externalizing problems. Of note, family functioning predicted significant variance in teacher-reported adolescent externalizing problems in the expected direction $(b=-.24, p \leq .05)$. See $\underline{\text { Table } 3}$ for more details.

\section{Sobel's test}

Significance testing of the indirect effect using Sobel's test indicated no significant indirect effects for acculturation differences on adolescent externalizing problems via family functioning.

\section{Bootstrapping procedures}

Bias-corrected bootstrapping procedures indicated no significant indirect effects for acculturation differences on adolescent internalizing problems via family functioning.

\section{Parental Outcomes}

\section{Causal steps method}

Results for mediation analyses for parental outcomes are presented in Table 4 . Parent-adolescent differences in LV had a significant, positive total effect on parental mental health outcomes $(\theta=.23, p \leq .05)$. Thus, differences in LV satisfied the first condition. LV did not have a significant total effect on family functioning (although it approached significance, $\beta=-.20, p \leq .10$ ) and therefore did not satisfy the second condition. Family functioning predicted significant variance in parental mental health $(\beta=-.28, p \leq .05)$, satisfying the third condition.

However, because not all conditions were met, results failed to support mediation based on this method. 
Table 4

Results of Mediation Analyses for Parental Outcomes: Causal Steps, Indirect Effects, and 95\% Confidence Interval for Bootstrapping Estimates

\begin{tabular}{|c|c|c|c|c|c|c|c|c|c|c|c|c|c|}
\hline \multirow[b]{2}{*}{ IV } & \multirow[b]{2}{*}{ Mediator } & \multirow[b]{2}{*}{ DV } & \multicolumn{2}{|c|}{$\begin{array}{l}\text { Total effect of } \\
\text { IV on DV (c) }\end{array}$} & \multicolumn{2}{|c|}{$\begin{array}{l}\text { Effects of IV } \\
\text { on mediator (a) }\end{array}$} & \multicolumn{2}{|c|}{$\begin{array}{l}\text { Effect of M } \\
\text { on DV (b) }\end{array}$} & \multicolumn{2}{|c|}{$\begin{array}{l}\text { Direct effects } \\
\text { (c1) }\end{array}$} & \multirow{2}{*}{$\begin{array}{c}\text { Indirect effect } \\
\qquad(\mathrm{a} \times \mathrm{b})\end{array}$} & \multicolumn{2}{|c|}{$95 \% \mathrm{CI}$} \\
\hline & & & B & Beta & B & Beta & B & Beta & B & Beta & & Lower & Upper \\
\hline LOS & Fam Fx & Par $\mathrm{MH}$ & 1.61 & .16 & $-2.71^{*}$ & $-.25^{*}$ & $-.28^{*}$ & $-.30^{\circ}$ & .94 & .09 & $.67^{+}$ & .10 & 1.8 \\
\hline LV & Fam Fx & Par MH & $3.74^{*}$ & $.23^{*}$ & $-3.46^{+}$ & $-.20^{+}$ & $-.28^{*}$ & $-.30^{\circ}$ & 2.93 & .18 & .8 & -.03 & 2.5 \\
\hline $\mathrm{AOS}$ & Fam Fx & Par MH & $-1.38^{+}$ & $-.18^{+}$ & $1.67^{+}$ & $.21^{+}$ & $-.28^{\circ}$ & $-.30^{\circ}$ & -.98 & -.13 & -.41 & -1.22 & -.02 \\
\hline AV & Fam Fx & Par $\mathrm{MH}$ & $2.72^{+}$ & $.21^{+}$ & 1.16 & .09 & $-.28^{*}$ & $-.30^{\circ}$ & $3.05^{\circ}$ & $.24^{*}$ & -.33 & -1.46 & .44 \\
\hline
\end{tabular}

Note. $\quad N=84$. LOS $=$ Latino behavioral acculturation differences; $\mathrm{LV}=$ Latino cognitive acculturation differences; AOS $=$ U.S. mainstream behavioral acculturation differences; $\mathrm{AV}=\mathrm{U} . \mathrm{S}$. mainstream cognitive acculturation differences; Fam Fx = parent-reported family functioning: Par $\mathrm{MH}=$ parent self-reported mental health symptoms. Bold values indicated significant confidence interval.

${ }^{*} p<.10 . *{ }^{*} p \leq .05$.

Table 4: Results of Mediation Analyses for Parental Outcomes: Causal Steps, Indirect Effects, and 95\% Confidence Interval for Bootstrapping Estimates

\begin{tabular}{|c|c|c|c|c|c|c|c|c|c|c|c|c|c|}
\hline & & & $\begin{array}{l}\text { Total } \\
\text { effect of } \\
\text { IV on DV } \\
\text { (c) }\end{array}$ & & $\begin{array}{l}\text { Effects of IV } \\
\text { on mediator } \\
\text { (a) }\end{array}$ & & $\begin{array}{l}\text { Effect of } \\
M \\
\text { on DV } \\
\text { (b) }\end{array}$ & & $\begin{array}{l}\text { Direct } \\
\text { effects } \\
\text { (c1) }\end{array}$ & & & $\begin{array}{l}95 \% \\
\mathrm{Cl} \\
\end{array}$ & \\
\hline IV & Mediator & DV & B & Beta & B & Beta & B & Beta & B & Beta & $\begin{array}{l}\text { Indirect } \\
\text { effect } \\
(a \times b)\end{array}$ & Lower & Upper \\
\hline LOS & Fam Fx & $\begin{array}{l}\text { Par } \\
\mathrm{MH}\end{array}$ & 1.61 & .16 & -2.71 & $.25^{*}$ & $-.28^{*}$ & $.30 *$ & .94 & .09 & $.67+$ & .10 & 1.82 \\
\hline LV & Fam Fx & $\begin{array}{l}\text { Par } \\
\mathrm{MH}\end{array}$ & $3.74{ }_{-}^{*}$ & $.23 *$ & -3.46 & $\begin{array}{r}- \\
.20+\end{array}$ & $-.28^{*}$ & $\begin{array}{r}- \\
.30 *\end{array}$ & 2.93 & .18 & .81 & -.03 & 2.59 \\
\hline AOS & Fam Fx & $\begin{array}{l}\text { Par } \\
\mathrm{MH}\end{array}$ & $-1.38+$ & $\begin{array}{r}- \\
.18+\end{array}$ & $1.67+$ & $.21+$ & $-.28^{*}$ & $\begin{array}{r}- \\
.30^{*}\end{array}$ & -.98 & -.13 & -.41 & -1.22 & -.02 \\
\hline AV & Fam Fx & $\begin{array}{l}\text { Par } \\
\mathrm{MH}\end{array}$ & $2.72++$ & $.21+$ & 1.16 & .09 & $-.28 *$ & $\begin{array}{r}- \\
.30^{*} \\
\end{array}$ & $3.05^{*}$ & $.24 *$ & -.33 & -1.46 & .44 \\
\hline
\end{tabular}

Note. $N=84$. LOS Latino behavioral acculturation differences; $\mathrm{LV}=$ Latino cognitive acculturation differences; AOS = U.S. mainstream behavioral acculturation differences; $A V=U . S$. mainstream cognitive acculturation differences; Fam $F x$ =parent-reported family functioning; Par $\mathrm{MH}$ = parent self-reported mental health symptoms. Bold values indicated significant confidence interval.

${ }^{+} p<.10{ }^{*} p<.05$.

\section{Sobel's test}

Mediation also was examined through significance testing of the indirect effect, using Sobel's test and indicated no significant indirect effects for acculturation differences on parental mental health outcomes.

\section{Bootstrapping procedures}

Results of bias-corrected bootstrapping procedures indicated that the indirect effect of LOS differences and of AOS differences on parental mental health via family functioning were significant ( $95 \%$ confidence interval $=.10$ to $1.82 ;-1.22$ to -.02 , respectively).

\section{Moderated Mediation Analyses}

The second hypothesis was that acculturation conflict would moderate the strength of the mediated relationship between acculturation differences and internalizing problems for adolescents, externalizing problems for adolescents, and mental health outcomes for parents, via family functioning, such that the mediated relationship would be weaker for low acculturation conflict. To test Hypothesis 2, moderated mediation analyses were conducted following guidelines outlined in Preacher et al. (2007). 
Conditional indirect effects

Results indicate that there were no significant conditional indirect effects for adolescent internalizing, adolescent externalizing, or parental outcomes.

\section{Bootstrapping procedures}

In addition, bias-corrected bootstrapping procedures with 5000 resamples were utilized to calculate $95 \%$ confidence intervals of the indirect effect at each level of the moderator. One confidence interval excluded zero, suggesting the presence of a significant conditional indirect effect for LV on teacher-reported externalizing problems via family functioning at high levels of acculturation conflict (conditional indirect effect $=1.84 ; 95 \% \mathrm{Cl}$ $=.19$ to 6.10$)$.

\section{Exploratory Post Hoc Analyses}

Given the significant relationship of acculturation conflict with several variables, yet limited findings for the moderated mediation analyses, additional post hoc analyses were conducted to further examine the role of acculturation conflict (see Table 5). Specifically, acculturation conflict by family functioning interactions on adolescent and parental mental health outcomes were examined using the procedure described by Aiken and West (1991). Variables were centered to avoid potential issues with multicollinearity. In addition, specific subscales of LV were examined for adolescent externalizing outcomes.

Table 5

Results of Moderation Analyses for Adolescent and Parental Outcomes

\begin{tabular}{cllccc}
\hline IV & Moderator & DV & $\begin{array}{c}\beta \text { for main effect } \\
\text { of IV }\end{array}$ & $\begin{array}{c}\beta \text { for main effect } \\
\text { of moderator }\end{array}$ & $\begin{array}{c}\beta \text { for interaction } \\
\text { term }\end{array}$ \\
\hline A Fam Fx & A Acc Conf & YSR-I & -.16 & $.39^{* *}$ & .12 \\
A Fam Fx & A Acc Conf & CBCL-E & -.15 & .23 & .02 \\
A Fam Fx & A Acc Conf & TRF-E & -.17 & -.02 & $.28^{*}$ \\
P Fam Fx & P Acc Conf & Par MH & -.16 & $.39^{*}$ & .12 \\
\hline
\end{tabular}

Note. $\quad N=83-84 . \mathrm{A}=$ adolescent variable; $p=$ parent variable; LOS $=$ Latino behavioral acculturation differences; $\mathrm{LV}=$ Latino cognitive acculturation differences; $\mathrm{AOS}=\mathrm{U} . \mathrm{S}$. mainstream behavioral acculturation differences; $\mathrm{AV}=\mathrm{U} . \mathrm{S}$. mainstream cognitive acculturation differences; Acc Conf $=$ acculturation conflict; Fam Fx $=$ parent-reported family functioning; YSR-I = adolescent-reported internalizing symptoms; CBCL-E = parent-reported adolescent externalizing symptoms; TRF-E = teacher-reported adolescent externalizing symptoms; Par $\mathrm{MH}=$ parent self-reported mental health symptoms.

${ }^{*} p \leq .05 . \quad{ }^{* *} p \leq .01$.

Table 5: Results of Moderation Analyses for Adolescent and Parental Outcomes

\begin{tabular}{|c|l|l|r|r|r|}
\hline & & & $\beta$ for main effect \\
of IV & \multicolumn{2}{|c|}{$\begin{array}{c}\beta \text { for main effect of } \\
\text { moderator }\end{array}$} & \multicolumn{2}{|c|}{$\begin{array}{c}\beta \text { for interaction } \\
\text { term }\end{array}$} \\
\hline A Fam Fx & Moderator & DV & -.16 & $.39^{* *}$ & .23 \\
\hline A Fam Fx & A Acc Conf & YSR-I Conf & CBCL-E & -.15 & .02 \\
\hline A Fam Fx & A Acc Conf & TRF-E & -.17 & .02 \\
\hline P Fam Fx & P Acc Conf & Par MH & -.16 & $.39^{*}$ & .12 \\
\hline
\end{tabular}

Note. $N=83-84 . \mathrm{A}=$ adolescent variable; $p=$ parent variable; LOS = Latino behavioral acculturation differences; LV = Latino cognitive acculturation differences; AOS = U.S. mainstream behavioral acculturation differences; AV = U.S. mainstream cognitive acculturation differences; Acc Conf = acculturation conflict; Fam Fx = parent-reported family functioning; YSR-I = adolescent-reported internalizing symptoms; $C B C L-E$ = parent-reported adolescent externalizing symptoms; TRF-E = teacher-reported adolescent externalizing symptoms; Par $\mathrm{MH}=$ parent self-reported mental health symptoms.

$p<.05$. $^{* *} p<.01$. 


\section{Adolescent internalizing outcomes}

Results did not support acculturation conflict as a moderator of the relationship between family functioning and adolescent internalizing problems. There was a significant main effect for acculturation conflict on adolescent internalizing symptoms $(\beta=.39, p \leq .01)$.

\section{Adolescent externalizing outcomes}

A significant interaction was found for acculturation conflict and family functioning on teacher-reported adolescent externalizing problems $(F=3.42, p \leq .05, \beta=.28)$. The interaction was plotted and the significance of the slopes was examined. The slope of the regression line of family functioning predicting adolescent externalizing problems at low levels of acculturation conflict was significant $(\beta=-0.44, p \leq .05)$, at moderate levels the slope approached significance $(\beta=-.036, p=.085)$, and at high levels the slope was not significant $(\beta=$ $.02, n s)$.

Additionally, given the significant relationship between LV and parent- and teacher-reported adolescent externalizing problems, such that adolescents with higher Latino cognitive acculturation had fewer externalizing problems (see above), specific subscales of LV were examined. Results indicated that parent and teacher reports of adolescent externalizing problems were negatively related to adolescent endorsement of the cultural values, as measured by the MACVS subscale, of familism, $r=-.30, p \leq .01 ; r=-.39, p \leq .001$, respectively and respect, $r=$ $-.41, p \leq .001 ; r=-.32, p \leq .01$, respectively. Teacher reports of adolescent externalizing problems also were negatively related to adolescent endorsement of the cultural value religion, $r=-.37, p \leq .001$.

Parental mental health outcomes

Results did not support acculturation conflict as a moderator of the relationship between family functioning and parental mental health outcomes. There was a significant main effect for acculturation conflict on parental mental health symptoms $(\beta=.39, p \leq .05)$.

\section{Discussion}

In order to help address the mental health disparities that exist for Latino families in the U.S., the current study sought to examine the acculturation-mental health link within the context of the family and to identify potential mechanisms for intervention to alleviate mental health problems in Latinos. Specifically, our goal was to examine how acculturation differences were related to mental health in Latino families and to understand the role of acculturation conflict and family functioning within the Latino family. We extended previous research by using comprehensive measures of acculturation, including measures of acculturation conflict, examining additional family variables, and exploring Latino family mental health contextually by including measures of parental mental health.

We found partial support for our hypothesis that family functioning mediates the relationship between acculturation differences, specifically differences in Latino and U.S. behavioral acculturation, and mental health outcomes for Latino parents. Additionally, we found partial support for our moderated mediation hypothesis; specifically, a significant conditional indirect effect was found for Latino cognitive acculturation differences on adolescent externalizing problems via family functioning at high levels of acculturation conflict. Exploratory analyses also indicated that acculturation conflict moderates the relationship between family functioning and externalizing problems for Latino adolescents and had a significant main effect for adolescent internalizing problems and parental mental health. 


\section{Adolescent Mental Health}

\section{Internalizing problems}

The current study did not find support for mediation or moderated mediation for the effect of acculturation differences on adolescent internalizing problems via family functioning. These findings are consistent with previous studies that have failed to find links between acculturation and internalizing problems (e.g., Katragadda \& Tidwell, 1998), as well as studies that have failed to find significant effects of acculturation gaps on family factors or mental health outcomes (Davidson \& Cardemil, 2009; Lau et al., 2005; Pasch et al., 2006; Smokowski et al., 2008). Therefore, our findings add to the growing body of literature that suggests, for adolescents, differences in cultural orientation within the family do not necessarily have negative implications for family functioning or internalizing mental health outcomes.

However, given evidence that Latino youth demonstrate similar or greater risk of mental health problems (CDC, 2004) compared to other groups, these null findings suggest the need to identify other factors that may explain this increased risk. Although acculturation differences did not predict mental health outcomes indirectly, we found that adolescent-reported acculturation conflict was positively related and had a significant main effect for internalizing symptoms, and family functioning was inversely related to adolescent internalizing problems, which is consistent with previous research in several ways. First, other research has found that positive family functioning, such as supportive parenting practices, is related to less risk for depression in Latino adolescents, whereas family conflict is related to greater risk (Gonzales et al., 2006). In addition, acculturative stress has been shown to be related to anxiety and depression (Crockett et al., 2007; Stein et al., 2012; Suarez-Moreles \& Lopez, $\underline{2009}$ ), and research has found that adolescent perceptions of acculturation differences or conflict are related to negative outcomes (Hwang \& Wood, 2009; Smokowski \& Bacallao, 2006). Our findings seem to support researchers who have argued that, in terms of the acculturation-mental health link, acculturation conflict is a more "salient" construct for understanding Latino adolescent outcomes (Smokowski et al., 2008), particularly for internalizing symptoms.

Additionally, although the findings regarding acculturation differences and mental health outcomes for adolescents were not significant, the significant relationship of acculturation conflict and internalizing symptoms suggests that determining the impact that acculturation has within the family is important. The meaning adolescents and their families make of cultural experiences appears important for predicting adolescent internalizing outcomes (Davidson \& Cardemil, 2009).

\section{Externalizing problems}

Surprisingly, our findings do not support previous research that has shown orientation to U.S. mainstream culture to be a risk factor for externalizing problems (Samaniego \& Gonzales, 1999; Sullivan et al., 2007), as U.S. acculturation was not related to mental health outcomes. However, results indicated that Latino cognitive acculturation was protective for adolescents, as it was negatively related to parent- and teacher-reported externalizing symptoms. Post hoc analyses indicated that adolescent endorsement of Latino cultural values of familism, respect, and religion was significantly related to fewer externalizing problems. These results support previous findings that adolescents who maintain traditional Latino cultural values have lower risk for externalizing problems. For example, Gonzales et al. (2008) also found that endorsement of Latino cultural values was related to fewer externalizing problems among 7th graders and that cultural values mediated the relationship between nativity status and externalizing problems.

Additionally, moderated mediation analyses help to further explain this relationship and help to address limitations in previous research examining the acculturation-mental health link by identifying more specifically how acculturation is related to mental health. Our findings suggest that parent-adolescent differences in Latino cognitive acculturation or cultural values affect adolescent externalizing problems indirectly through family 
functioning, but only at high levels of acculturation conflict. Thus, it appears that acculturation differences are influential for adolescent externalizing behavior and family functioning when conflict regarding these differences is high. Post hoc analyses indicated that acculturation conflict moderated the relationship between family functioning and parent-reported externalizing problems. Specifically, a low level of acculturation conflict was a protective factor against externalizing problems for adolescents. Adolescents whose families had high acculturation conflict continued to be a risk for externalizing problems regardless of the family's functioning.

Taken together, the results suggest that orientation to traditional Latino values is important for Latino adolescents' mental health in several ways. First, Latino adolescents' own orientation to traditional Latino values may reduce their risk for externalizing problems by giving them access to cultural resources, such as their family and their religion, which is supported by our post hoc analyses as well as previous research. For example, Latino families who value familism, the cultural value emphasizing strong attachment to and reliance on the family (Cauce \& Domenech-Rodriguez, 2002), may socialize their children in a way that promotes pro-social behavior (Calderón-Tena, Knight, \& Carlo, 2011), reducing the risk for externalizing problems. Familism may also protect Latino adolescents from the negative influence of deviant peers (Germán, Gonzales, \& Dumka, 2009). In addition, strong religious beliefs, another aspect of traditional Latino culture, are associated with lower risk for externalizing problems (see Johnson, De Li, Larson, \& McCullough, 2000for a review).

Our results also suggest that differences between adolescents and their parents in terms of their orientation to Latino cultural values do not necessarily result in problems for adolescents, perhaps because some families expect these differences to occur over time or view these differences positively, such as allowing their adolescent to access mainstream resources (Davidson \& Cardemil, 2009). However, when parents and adolescents have high levels of conflict surrounding acculturation, these differences may negatively impact family functioning, which may increase risk for externalizing problems. Results of post hoc analyses suggest that acculturation conflict may "undo" the benefits that good family communication and satisfaction have on reducing externalizing behavior; these findings are similar to those of Marsiglia and colleagues (2014), who found that greater cultural distance between adolescents and parents weakens the protective effect of parental monitoring on externalizing problems.

\section{Parental Mental Health}

Similar to previous studies that have failed to find a link between acculturation and adult mental health outcomes (e.g., Shurgot, \& Knight, 2004), the current study did not find significant relationships between parental mental health outcomes and any parental acculturation variables. However, through examination of acculturation within the context of the family, specifically parent-adolescent acculturation differences, we found that Latino and U.S. behavioral acculturation differences affect parental mental health outcomes indirectly via family functioning. For parents, differences in Latino behavioral acculturation were negatively related to family functioning, and family functioning was negatively related to parental mental health problems. On the other hand, differences in U.S. behavioral acculturation were positively related to family functioning, which was inversely related to mental health. While the current study, to our knowledge, is the first to examine parental mental health in the context of family acculturation, these findings are consistent with previous research that has found links between acculturation and adult mental health outcomes for Latinos (e.g., Chamorro \& Flores-Ortiz, 2000; Cuellar et al., 2004) and help to address some of the inconsistencies and limitations in this previous work by providing information about why and how acculturation is related to mental health.

Our findings suggest that acculturation is important for understanding Latino mental health within the context of the family. While parents' individual cultural orientation was not related to mental health outcomes, differences in cultural orientation with their child, specifically behavioral acculturation, as well as family 
functioning, was associated with increased parental mental health problems. It seems that it is not one's individual cultural orientation by itself that may increase risk for mental health problems but rather how it unfolds within the context of the family. The significant findings related to behavioral acculturation and the mediating role of family functioning, as well as the lack of findings related to cognitive acculturation, suggest that acculturation differences may negatively influence the way family members interact with each other. These differences may affect their ability to solve problems effectively or negatively influence their relationship, putting parents at risk for depression and anxiety, particularly if they feel rejected by their child.

Interestingly, in contrast with findings for adolescents, results did not provide evidence of acculturation conflict as a moderator, as no conditional indirect effects were significant, nor were post hoc simple moderation analyses significant for parental outcomes. This suggests that acculturation differences may be important for Latino parents' perceptions of family functioning and mental health, regardless of level of acculturation conflict. Overall, the different pattern of findings for parents and adolescents suggests that there are distinct risk factors for different family members.

It also should be noted that results differed based on analytic method. For mediation analyses, although there were some trends based on the causal steps method and Sobel's test, only the bootstrapping method resulted in significant findings. In addition, only the bootstrapping methods resulted in significant findings for moderated mediation analyses. The lack of findings based on the causal steps method and Sobel's test are likely the result of limited power due to the small sample size, and suggests that the use of bootstrapping methods or more sophisticated methods, such as structural equation modeling, is important for future studies.

\section{Limitations}

There are several limitations of the current study that should be noted. First, the sample is relatively small and did not allow us to use more sophisticated analytic strategies or to examine subgroups, due to limited power. The sample also is not nationally representative, which may influence the results. In addition, the small interrater correlations for some variables did not allow us to create composites and take multiple ratings into account. Additionally, another important limitation to consider is the assumption of the acculturation conflict measure that adolescents acculturate to U.S. culture faster than parents. Finally, the current study used a correlational design, which does not allow for determination of causality and may have increased the risk of Type I error.

\section{Conclusions and Future Directions}

Despite these limitations, results of the current study support several important conclusions. Acculturation is an important factor for understanding mental health within Latino families and seems to impact adolescents and their parents differently. Differences in Latino cognitive acculturation were influential for adolescent mental health, but only at high levels of acculturation conflict. Additionally, positive family functioning decreased risk for adolescent externalizing problems, except at high levels of acculturation conflict. Overall, acculturation conflict seems to be a more important construct for understanding acculturation and Latino adolescent mental health in our study, compared to acculturation differences, supporting the findings of previous research (Smokowski et al., 2008). Future research should examine other predictors of Latino adolescent mental health, such as the impact of discrimination, as well as peer influences, as these will further our understanding of the Latino adolescents' cultural context.

In contrast, acculturation differences were important for Latino parental mental health, regardless of level of acculturation conflict. Differences in Latino behavioral acculturation were negatively related to family functioning, whereas differences in U.S. behavioral acculturation were positively related to family functioning, perhaps due to expectations of such differences or perceptions of increased access to mainstream resources. 
Thus, it is important to determine how parents and families interpret and understand differences in the cultural orientation between themselves and their children.

Overall, our results highlight the importance of understanding acculturation within the context of the Latino family and suggest that differences in acculturation may not always be problematic and likely depend on how families interpret acculturation differences. Future research should examine what factors may influence families' view of acculturation differences as positive or negative. Additionally, given the availability of interventions aimed at facilitating family biculturalism, such as Bicultural Effectiveness Training (Szapocznik et al., 1984), Las Familias Unidas (Coatsworth, Pantin, \& Szapocznik, 2002) and Entre Dos Mundos (Bacallao \& Smokowski, 2005), future research should examine which families would benefit the most from bicultural family therapy. Further dissemination of such interventions may help to address the increased risk of mental health problems and reduce mental health disparities in this population.

\section{References}

Achenbach, T. M., \& Rescorla, L. A. (2001). Manual for the ASEBA school-age forms \& profiles. Burlington, VT: University of Vermont, Research Center for Children, Youth, \& Families.

Aiken, L. S., \& West, S. G. (1991). Multiple regression: Testing and interpreting interactions. Thousand Oaks, CA: Sage.

Androff, D. K., Ayon, C., Becerra, D., Gurrola, M., Salas, L., Krysik, J., .. .Segal, E. (2011). U.S. immigration policy and immigrant children's well-being: The impact of policy shifts. Journal of Sociology and Social Welfare, 38, 77-98.

Bacallao, M. L., \& Smokowski, P. R. (2005). "Entre dos mundos” (Between Two Worlds): Bicultural skills training with Latino immigrant families. The Journal of Primary Prevention, 26, 485-509. 10.1007/s10935-0050008-6

Bámaca-Colbert, M. Y., \& Gayles, J. G. (2010). Variable-centered and person-centered approaches to studying Mexican-origin mother-daughter cultural orientation dissonance. Journal of Youth and Adolescence, 39, 1274-1292. 10.1007/s10964-009-9447-3

Baron, R. M., \& Kenny, D. A. (1986). The moderator-mediator variable distinction in social psychological research: Conceptual, strategic, and statistical considerations. Journal of Personality and Social Psychology, 51, 1173-1182. 10.1037/0022-3514.51.6.1173

Beck, A. T., Epstein, N., Brown, G., \& Steer, R. A. (1988). An inventory for measuring clinical anxiety: Psychometric properties. Journal of Consulting and Clinical Psychology, 56, 893-897. 10.1037/0022006X.56.6.893

Beck, A. T., \& Steer, R. A. (1993). Manual for the Beck Anxiety Inventory. San Antonio, TX: Psychological Corporation.

Beck, A. T., Steer, R. A., \& Brown, G. K. (1996). Manual for the Beck Depression Inventory-II. San Antonio, TX: Psychological Corporation.

Berry, J. W. (1997). Immigration, acculturation, and adaptation. Applied Psychology, 46, 5-68.

Berry, J. W. (2001). A psychology of immigration. Journal of Social Issues, 57, 615-631. 10.1111/00224537.00231

Berry, J. W. (2006). Contexts of acculturation. In D.Sam \& J.Berry (Eds.), The Cambridge handbook of acculturation psychology (pp. 27-42). New York, NY: Cambridge University Press. 10.1017/СВ09780511489891.006

Burnett-Zeigler, I., Bohnert, K. M., \& Ilgen, M. A. (2013). Ethnic identity, acculturation and the prevalence of lifetime psychiatric disorders among black, Hispanic, and Asian adults in the U.S. Journal of Psychiatric Research, 47, 56-63. 10.1016/j.jpsychires.2012.08.029 
Cabassa, L. J. (2003). Measuring acculturation: Where we are and where we need to go. Hispanic Journal of Behavioral Sciences, 25, 127-146. 10.1177/0739986303025002001

Calderón-Tena, C. O., Knight, G. P., \& Carlo, G. (2011). The socialization of prosocial behavioral tendencies among Mexican American adolescents: The role of familism values. Cultural Diversity \& Ethnic Minority Psychology, 17, 98-106. 10.1037/a0021825

Cauce, A. M., \& Domenech-Rodríguez, M. (2002). Latino families: Myths and realities. In J.Contreras, K.Kerns, \& A.Neal-Barnett (Eds.), Latino children and families in the United States: Current research and future directions (pp. 3-25). Westport, CT: Praeger/Greenwood.

CDC. (2004). Surveillance summaries, May 21, 2004, MMWR 2004:53(No. SS-2). Retrieved from http://www.cdc.gov/mmwr/PDF/SS/SS5302.pdf

Céspedes, Y. M., \& Huey, S. J., Jr. (2008). Depression in Latino adolescents: A cultural discrepancy perspective. Cultural Diversity \& Ethnic Minority Psychology, 14, 168-172. 10.1037/1099-9809.14.2.168

Chamorro, R., \& Flores-Ortiz, Y. (2000). Acculturation and disordered eating patterns among Mexican American women. International Journal of Eating Disorders, 28, 125-129.

Coatsworth, J. D., Pantin, H., \& Szapocznik, J. (2002). Familias Unidas: A family-centered ecodevelopmental intervention to reduce risk for problem behavior among Hispanic adolescents. Clinical Child and Family Psychology Review, 5, 113-132. 10.1023/A:1015420503275

Crockett, L. J., Iturbide, M. I., Torres Stone, R. A., McGinley, M., Raffaelli, M., \& Carlo, G. (2007). Acculturative stress, social support, and coping: Relations to psychological adjustment among Mexican American college students. Cultural Diversity \& Ethnic Minority Psychology, 13, 347-355. 10.1037/10999809.13.4.347

Cuellar, I., Arnold, B., \& Maldonado, R. (1995). Acculturation Rating Scale for Mexican-Americans-ll: A revision of the original ARSMA Scale. Hispanic Journal of Behavioral Sciences, 17, 275-304. 10.1177/07399863950173001

Cuellar, I., Bastida, E., \& Braccio, S. M. (2004). Residency in the United States, subjective well-being, and depression in an older Mexican-origin sample. Journal of Aging and Health, 16, 447-466. $10.1177 / 0898264304265764$

Davidson, T. M., \& Cardemil, E. V. (2009). Parent-child communication and parental involvement in Latino adolescents. The Journal of Early Adolescence, 29, 99-121. 10.1177/0272431608324480

Dawson, B. A., \& Williams, S. A. (2008). The impact of language status as an acculturative stressor on internalizing and externalizing behaviors among Latino/a children: A longitudinal analysis from school entry through third grade. Journal of Youth and Adolescence, 37, 399-411. 10.1007/s10964-007-9233-z

Duarte, C. S., Bird, H. R., Shrout, P. E., Wu, P., Lewis-Fernandéz, R., Shen, S., \& Canino, G. (2008). Culture and psychiatric symptoms in Puerto Rican children: Longitudinal results from one ethnic group in two contexts. Journal of Child Psychology and Psychiatry, 49, 563-572. 10.1111/j.1469-7610.2007.01863.x

Ennis, S. R., Rios-Vargas, M., \& Albert, N. G. (2011). The Hispanic population: 2010. Retrieved from the U.S. Census Bureau website:http://www.census.gov/prod/cen2010/briefs/c2010br-04.pdf

Fry, R., \& Passel, J. S. (2009). Latino children: A majority are U.S.-born offspring of immigrants. Washington, DC: Pew Hispanic Center.

Germán, M., Gonzales, N. A., \& Dumka, L. (2009). Familism values as a protective factor for Mexican-origin adolescents exposed to deviant peers. The Journal of Early Adolescence, 29, 16-42. $10.1177 / 0272431608324475$

Gil, A. G., Wagner, E. F., \& Vega, W. A. (2000). Acculturation, familism, and alcohol use among Latino adolescent males: Longitudinal relations. Journal of Community Psychology, 28, 443-458. 10.1002/15206629(200007)28:4<443::AID-JCOP6>3.0.CO;2-A 
Gonzales, N. A., Deardorff, J., Formoso, D., Barr, A., \& Barrera, M. (2006). Family mediators of the relation between acculturation and adolescent mental health. Family Relations, 55, 318-330. 10.1111/j.17413729.2006.00405.x

Gonzales, N. A., Germán, M., Kim, S. Y., George, P., Fabrett, F. C., Millsap, R., \& Dumka, L. E. (2008). Mexican American adolescents' cultural orientation, externalizing behavior and academic engagement: The role of traditional cultural values. American Journal of Community Psychology, 41, 151-164. 10.1007/s10464007-9152-x

Gowen, L. K., Hayward, C., Killen, J. D., Robinson, T. N., \& Taylor, C. B. (1999). Acculturation and eating disorder symptoms in adolescent girls. Journal of Research on Adolescence, 9, 67-83.

10.1207/s15327795jra0901_4

Groenenberg, I., Sharma, S., Green, B. S., \& Fleming, S. E. (2013). Family environment in inner-city African American and Latino parents/caregivers: A comparison of the reliability of instruments. Journal of Child and Family Studies, 22, 288-296. 10.1007/s10826-012-9578-0

Hayes, A. F. (2009). Beyond Baron and Kenny: Statistical mediation analysis in the new millennium. Communication Monographs, 76, 408-420. 10.1080/03637750903310360

Huq, N., Stein, G. L., \& Gonzalez, L. M. (2016). Acculturation conflict among Latino youth: Discrimination, ethnic identity, and depressive symptoms. Cultural Diversity \& Ethnic Minority Psychology, 22, 377-385.

Hwang, W.-C., \& Wood, J. J. (2009). Acculturative family distancing: Links with self-reported symptomatology among Asian Americans and Latinos. Child Psychiatry and Human Development, 40, 123-138. 10.1007/s10578-008-0115-8

Johnson, B. R., De Li, S., Larson, D. B., \& McCullough, M. (2000). A systematic review of the religiosity and delinquency literature: A research note. Journal of Contemporary Criminal Justice, 16, 32-52. $10.1177 / 1043986200016001003$

Katragadda, C. P., \& Tidwell, R. (1998). Rural Hispanic adolescents at risk for depressive symptoms. Journal of Applied Social Psychology, 28, 1916-1930. 10.1111/j.1559-1816.1998.tb01353.x

Knight, G. P., Gonzales, N. A., Saenz, D. S., Bonds, D. D., Germán, M., Deardorff, J., . . Updegraff, K. A. (2010). The Mexican American Cultural Values scales for Adolescents and Adults. The Journal of Early Adolescence, 30, 444-481. 10.1177/0272431609338178

Knight, G. P., Virdin, L. M., \& Roosa, M. (1994). Socialization and family correlates of mental health outcomes among Hispanic and Anglo American children: Consideration of cross-ethnic scalar equivalence. Child Development, 65, 212-224. 10.2307/1131376

Koneru, V. K., Weisman de Mamani, A. G., Flynn, P. M., \& Betancourt, H. (2007). Acculturation and mental health: Current findings and recommendations for future research. Applied \& Preventive Psychology, 12, 76-96. 10.1016/j.appsy.2007.07.016

Lau, A. S., McCabe, K. M., Yeh, M., Garland, A. F., Wood, P. A., \& Hough, R. L. (2005). The acculturation gapdistress hypothesis among high-risk Mexican American families. Journal of Family Psychology, 19, 367375. 10.1037/0893-3200.19.3.367

Lawton, K. E., \& Gerdes, A. C. (2014). Acculturation and Latino adolescent mental health: Integration of individual, environmental, and family influences. Clinical Child and Family Psychology Review, 17, 385398. 10.1007/s10567-014-0168-0

Lawton, K. E., Gerdes, A. C., Haack, L. M., \& Schneider, B. (2014). Acculturation, cultural values, and Latino parental beliefs about the etiology of ADHD. Administration and Policy in Mental Health and Mental Health Services Research, 41, 189-204. 10.1007/s10488-012-0447-3

Lorenzo-Blanco, E. I., Unger, J. B., Ritt-Olson, A., Soto, D., \& Baezconde-Garbanati, L. (2011). Acculturation, gender, depression, and cigarette smoking among U.S. Hispanic youth: The mediating role of perceived discrimination. Journal of Youth and Adolescence, 40, 1519-1533. 10.1007/s10964-011-9633-y 
MacKinnon, D. P., Lockwood, C. M., Hoffman, J. M., West, S. G., \& Sheets, V. (2002). A comparison of methods to test mediation and other intervening variable effects. Psychological Methods, 7, 83-104. 10.1037/1082989X.7.1.83

Magán, I., Sanz, J., \& García-Vera, M. P. (2008). Psychometric properties of a Spanish version of the Beck Anxiety Inventory (BAI) in general population. The Spanish Journal of Psychology, 11, 626-640.

Marsiglia, F. F., Nagoshi, J. L., Parsai, M., Booth, J. M., \& Castro, F. G. (2014). The parent-child acculturation gap, parental monitoring, and substance use in Mexican heritage adolescents in Mexican neighborhoods of the southwest U.S. Journal of Community Psychology, 42, 530-543. 10.1002/jcop.21635

Martinez, C. R. (2006). Effects of differential family acculturation on Latino adolescent substance use. Family Relations, 55, 306-317. 10.1111/j.1741-3729.2006.00404.x

Martinez, O., Wu, E., Sandfort, T., Dodge, B., Carballo-Dieguez, A., Pinto, R., . . Chavez-Baray, S. (2015). Evaluating the impact of immigration policies on health status among undocumented immigrants: $A$ systematic review. Journal of Immigrant and Minority Health, 17, 947-970. 10.1007/s10903-013-9968-4

McQueen, A., Getz, J. G., \& Bray, J. H. (2003). Acculturation, substance use, and deviant behavior: Examining separation and family conflict as mediators. Child Development, 74, 1737-1750. 10.1046/j.14678624.2003.00635.x

Merikangas, K. R., He, J. P., Burstein, M., Swanson, S. A., Avenevoli, S., Cui, L., . . Swendsen, J. (2010). Lifetime prevalence of mental disorders in U.S. adolescents: Results from the National Comorbidity Survey Replication-Adolescent Suppl. (NCS-A). Journal of the American Academy of Child \& Adolescent Psychiatry, 49, 980-989. 10.1016/j.jaac.2010.05.017

Merikangas, K. R., He, J. P., Burstein, M., Swendsen, J., Avenevoli, S., Case, B., . . Olfson, M. (2011). Service utilization for lifetime mental disorders in U.S. adolescents: Results of the National Comorbidity Survey-Adolescent Suppl. (NCS-A). Journal of the American Academy of Child \& Adolescent Psychiatry, 50, 32-45. 10.1016/j.jaac.2010.10.006

Nguyen, A. M. D., \& Benet-Martínez, V. (2013). Biculturalism and adjustment: A meta-analysis. Journal of CrossCultural Psychology, 44, 122-159. 10.1177/0022022111435097

Nguyen, H. H. (2006). Acculturation in the United States. In D.Sam, \& J.Berry (Eds.), The Cambridge handbook of acculturation psychology (311-348). New York, NY: Cambridge University Press. 10.1017/СBO9780511489891.024

Nwosu, C., Batalova, J., \& Auclair, G. (2014). Frequently requested statistics on immigrants and immigration in the United States. Washington, DC: Migration Policy Institute.

Olson, D. (2011). FACES IV and the Circumplex Model: Validation study. Journal of Marital and Family Therapy, 37, 64-80. 10.1111/j.1752-0606.2009.00175.x

Pasch, L. A., Deardorff, J., Tschann, J. M., Flores, E., Penilla, C., \& Pantoja, P. (2006). Acculturation, parentadolescent conflict, and adolescent adjustment in Mexican American families. Family Process, 45, 75-86. 10.1111/j.1545-5300.2006.00081.x

Preacher, K. J., \& Hayes, A. F. (2004). SPSS and SAS procedures for estimating indirect effects in simple mediation models. Behavior Research Methods, Instruments, \& Computers, 36, 717-731. 10.3758/BF03206553

Preacher, K. J., Rucker, D. D., \& Hayes, A. F. (2007). Addressing moderated mediation hypotheses: Theory, methods, and prescriptions. Multivariate Behavioral Research, 42, 185-227. 10.1080/00273170701341316

Rivero, N., Martinez-Pampliega, A., \& Olson, D. H. (2010). Spanish adaptation of the FACES IV questionnaire: Psychometric characteristics. The Family Journal, 18, 288-296. 10.1177/1066480710372084

Romero, A. J., \& Roberts, R. E. (2003). Stress within a bicultural context for adolescents of Mexican descent. Cultural Diversity and Ethnic Minority Psychology, 9, 171-184. 10.1037/1099-9809.9.2.171 
Rubio-Stipec, M., Bird, H., Canino, G., \& Gould, M. (1990). The internal consistency and concurrent validity of a Spanish translation of the Child Behavior Checklist. Journal of Abnormal Child Psychology, 18, 393-406. 10.1007/BF00917642

Ryder, A. G., Alden, L. E., \& Paulhus, D. L. (2000). Is acculturation unidimensional or bidimensional? A head-tohead comparison in the prediction of personality, self-identity, and adjustment. Journal of Personality and Social Psychology, 79, 49-65. 10.1037/0022-3514.79.1.49

Samaniego, R. Y., \& Gonzales, N. A. (1999). Multiple mediators of the effects of acculturation status on delinquency for Mexican American adolescents. American Journal of Community Psychology, 27, 189210. 10.1023/A:1022883601126

Schwartz, S. J., Pantin, H., Sullivan, S., Prado, G., \& Szapocznik, J. (2006). Nativity and years in the receiving culture as markers of acculturation in ethnic enclaves. Journal of Cross-Cultural Psychology, 37, 345-353. $10.1177 / 0022022106286928$

Schwartz, S. J., Unger, J. B., Zamboanga, B. L., \& Szapocznik, J. (2010). Rethinking the concept of acculturation: Implications for theory and research. American Psychologist, 65, 237-251. 10.1037/a0019330

Shurgot, G. S., \& Knight, B. G. (2004). Preliminary study investigating acculturation, cultural values, and psychological distress in Latino caregivers of dementia patients. Journal of Mental Health and Aging, 10, 183-194.

Smith, S. R. (2007). Making sense of multiple informants in child and adolescent psychopathology: A guide for clinicians. Journal of Psychoeducational Assessment, 25, 139-149. 10.1177/0734282906296233

Smokowski, P. R., \& Bacallao, M. L. (2006). Acculturation and aggression in Latino adolescents: A structural model focusing on cultural risk factors and assets. Journal of Abnormal Child Psychology, 34, 657-673. 10.1007/s10802-006-9049-4

Smokowski, P. R., \& Bacallao, M. L. (2007). Acculturation, internalizing mental health symptoms, and selfesteem: Cultural experiences of Latino adolescents in North Carolina. Child Psychiatry and Human Development, 37, 273-292. 10.1007/s10578-006-0035-4

Smokowski, P. R., Rose, R., \& Bacallao, M. L. (2008). Acculturation and Latino family processes: How cultural involvement, biculturalism, and acculturation gaps influence family dynamics. Family Relations, 57, 295308. 10.1111/j.1741-3729.2008.00501.x

Smokowski, P. R., Rose, R. A., \& Bacallao, M. (2010). Influence of risk factors and cultural assets on Latino adolescents' trajectories of self-esteem and internalizing symptoms. Child Psychiatry and Human Development, 41, 133-155. 10.1007/s10578-009-0157-6

Sobel, M. E. (1982). Asymptotic intervals for indirect effects in structural equations models. Sociological Methodology, 13, 290-312. San Francisco, CA: Jossey-Bass. 10.2307/270723

Stein, G. L., Gonzalez, L. M., \& Huq, N. (2012). Cultural stressors and the hopelessness model of depressive symptoms in Latino adolescents. Journal of Youth and Adolescence, 41, 1339-1349. 10.1007/s10964012-9765-8

Suarez-Morales, L., \& Lopez, B. (2009). The impact of acculturative stress and daily hassles on pre-adolescent psychological adjustment: Examining anxiety symptoms. The Journal of Primary Prevention, 30, 335-349. 10.1007/s10935-009-0175-y

Sullivan, S., Schwartz, S. J., Prado, G., Huang, S., Pantin, H., \& Szapocznik, J. (2007). A bidimensional model of acculturation for examining differences in family functioning and behavior problems in Hispanic immigrant adolescents. The Journal of Early Adolescence, 27, 405-430. 10.1177/0272431607302939

Szapocznik, J., Santisteban, D., Kurtines, W., Perez-Vidal, A., \& Hervis, O. (1984). Bicultural effectiveness training: A treatment intervention for enhancing intercultural adjustment in Cuban American families. Hispanic Journal of Behavioral Sciences, 6, 317-344. 10.1177/07399863840064001

U.S. Census Bureau. (2016, October12). Profile America facts for features. Retrieved from http://www.census.gov/newsroom/facts-for-features/2016/cb16-ff16.html 
Vega, W. A., Alderete, E., Kolody, B., \& Aguilar-Gaxiola, S. (1998). Illicit drug use among Mexicans and Mexican Americans in California: The effects of gender and acculturation. Addiction, 93, 1839-1850. 10.1046/j.1360-0443.1998.931218399.x

Vega, W. A., Khoury, E. I., Zimmerman, R. S., Gil, A. G., \& Warheit, G. J. (1995). Cultural conflicts and problem behaviors of Latino adolescents in home and school environments. Journal of Community Psychology, 23, 167-179. 10.1002/1520-6629(199504)23:2<167::AID-JCOP2290230207>3.0.CO;2-O

Vega, W. A., Zimmerman, R., Gil, A., Warheit, G. J., \& Apospori, E. (1993). Acculturation strain theory: Its application in explaining drug use behavior among Cuban and other Hispanic youth. Drug Abuse Among Minority Youth: Advances in Research and Methodology, 130, 144-166.

Wiebe, J. S., \& Penley, J. A. (2005). A psychometric comparison of the Beck Depression Inventory-II in English and Spanish. Psychological Assessment, 17, 481-485. 10.1037/1040-3590.17.4.481

Zamboanga, B. L., Schwartz, S. J., Jarvis, L. H., \& Van Tyne, K. (2009). Acculturation and substance use among Hispanic early adolescents: Investigating the mediating roles of acculturative stress and self-esteem. The Journal of Primary Prevention, 30, 315-333. 10.1007/s10935-009-0182-z

Zayas, L. H., Bright, C. L., Alvarez-Sánchez, T., \& Cabassa, L. J. (2009). Acculturation, familism and motherdaughter relations among suicidal and non-suicidal adolescent Latinas. The Journal of Primary Prevention, 30, 351-369. 10.1007/s10935-009-0181-0

Submitted: November 22, 2015 Revised: November 22, 2016 Accepted: December 13, 2016

This publication is protected by US and international copyright laws and its content may not be copied without the copyright holders express written permission except for the print or download capabilities of the retrieval software used for access. This content is intended solely for the use of the individual user.

Source: Journal of Latinx Psychology. Vol. 6. (2), May, 2018 pp. 94-114)

Accession Number: 2017-09410-001

Digital Object Identifier: 10.1037/lat0000084 